This PDF is a selection from a published volume from the National Bureau of Economic Research

Volume Title: Frontiers in Health Policy Research, Volume 5

Volume Author/Editor: Alan M. Garber, editor

Volume Publisher: MIT Press

Volume ISBN: 0-262-07234-3

Volume URL: http://www.nber.org/books/garb02-1

Conference Date: June 7, 2001

Publication Date: January 2002

Title: Effects of Competition Under Prospective Payment on Hospital Costs Among High- and Low-Cost Admissions: Evidence from California, 1983 and 1993

Author: David Meltzer, Jeanette Chung URL: http://www.nber.org/chapters/c9858 


\title{
Effects of Competition Under Prospective Payment on Hospital Costs Among High- and Low-Cost Admissions: Evidence from California, 1983 and 1993
}

\author{
David Meltzer, University of Chicago \\ Jeanette Chung, University of Chicago
}

\section{Executive Summary}

Competition and prospective payment systems have been widely used to attempt to control health care costs. Although much of the increase in medical costs over the past half-century has been concentrated among a few high-cost users of health care, prospective payment systems may provide incentives to reduce expenditures selectively on high-cost users relative to low-cost users, and this pressure may be increased by competition. We use data on hospital charges and cost-to-charge ratios from California in 1983 and 1993 to examine the effects of competition on costs for high- and low-cost admissions before and after the establishment of the Medicare Prospective Payment System (PPS). Comparing persons above and below age 65 before and after the establishment of PPS, we find that competition is associated with increased costs before PPS in both age groups, but decreased costs afterwards, especially among those above age 65 with the highest costs. We conclude that the combination of competition and prospective payment systems may result in incentives to reduce spending selectively among the most expensive patients. This conclusion raises important issues relevant to the use of competition and prospective payment to control costs. It also implies that, at minimum, there is a need to carefully monitor outcomes for the sickest patients under prospective payment systems in competitive environments.

\section{Introduction}

After a half-century of extraordinary growth in health care expenditures in the United States, there is now evidence that health care spending growth is slowing. Why this is occurring and how long it may last is not known, but a substantial body of literature suggests that two key elements of the efforts to contain costs may have played a role: the use of prospective payment systems (Russell and Manning 1989) and the encouragement of competition among providers (Melnick and Zwanziger 1988). Indeed, the combination of these two approaches seems to 
be particularly important because competition in the absence of prospective payment systems has been suggested to increase costs (Robinson and Luft 1985), and prospective payment in the absence of competition provides no financial incentive to provide quality care.

While most theoretical discussions of the effects of prospective payment hinge on the incentives to provide lower levels of care under fixed reimbursement and do not discuss the differential incentives to provide care to different types of patients, ${ }^{1}$ a few theoretical examinations of prospective payment have also incorporated the differential incentives for spending on profitable and unprofitable patients (for example, Allen and Gertler 1991, Ellis 1998). Meanwhile, several empirical studies have examined the differential effects of prospective payment systems on low- and high-cost patients. For example, Ellis and McGuire (1996) show how prospective payment for mental health services under Medicaid in New Hampshire resulted in reduced expenditures selectively among the sickest patients. In the context of the Medicare PPS, Newhouse (1989) finds that, while patients in unprofitable diagnosis related groups (DRGs) were not more likely than other patients to be transferred under PPS, they are more likely to be found in "hospitals of last resort," suggesting that there is selection according to profitability. Similarly, Meltzer and Chung (2000) show that hospital spending for the elderly in California under Medicare PPS was selectively reduced among the most expensive patients. Indeed, these reductions occurred despite an overall pattern among the young and elderly prior to the implementation of Medicare PPS for cost growth to be greatest among the most expensive patients, as reflected in the increasing concentration of health care expenditures over this century (Cutler and Meara 1998). Meltzer and Chung show that this same pattern of selective cost reduction for the most expensive patients is present within the twelve largest DRGs, the categories by which Medicare reimburses hospitals under PPS.

The possibility that prospective payment systems may lead to a redistribution of resources from sick and costly persons within a payment category to healthier and more profitable ones cuts, in many ways, against a fundamental tenet behind prospective payment systems: namely, the subsidization of unprofitable patients by the profitable. Nevertheless, competitive pressures could lead to such an outcome as hospitals that attempt to support the care of unprofitable patients with revenue from profitable ones find the profitable patients wooed away by other hospitals that have chosen to invest resources in 
amenities that may appeal to patients and their doctors, but that are not necessarily directly associated with producing better outcomes for the most severely ill.

In this paper, we use California data on patient charges and hospital cost-to-charge ratios from 1983 and 1993 to explore the effects of competition under prospective payment on hospital costs for low- and high-cost admissions within the twelve largest DRGs. ${ }^{2}$ Since Medicare PPS was implemented nationwide by states nearly simultaneously, we have to identify the effects of PPS on hospital costs mainly through temporal cross-sectional analyses rather than cross-state analyses. In an attempt to separate the effects of PPS from temporal changes in market competition, however, we contrast the effects of competition on costs for admissions of persons older than 65 versus costs for admissions of persons under 65. Complicating this analysis is the consideration of contemporaneous changes in the organization and financing of MediCal, California's Medicaid agency. In particular, the development of a selective provider contracting program and per-diem reimbursement system by Medi-Cal, in addition to the increasing use of managed care arrangements, all contributed to suppressing hospital growth among the young in California over the 1983-1993 period.

Although we cannot prove that the patterns we observe are due to Medicare PPS, we find clear evidence that increased competition is associated with increased costs among the elderly before the implementation of PPS, but decreased costs afterward, with the reductions in costs clearly much greater among high-cost admissions than among low-cost admissions. This is consistent with the idea that the incentives created by Medicare PPS may have selectively reduced expenditures on the high-cost elderly.

We begin in Section II with a short overview of the most important cost-containment efforts prevailing in California during this period: the Medicare Prospective Payment System, the California Medi-Cal selective provider contracting program, and the expansion of managed care. The description of PPS provides the institutional context for the effects of PPS we aim to investigate, while the discussion of the changes in reimbursement strategies among the young provides some insight into the use of the temporal changes in the effects of competition on costs for the young as a comparison. In Section III, we develop the theoretical motivation for our analyses using a model of provider response to fixed-rate, prospective reimbursement, in which quality can be varied for patients who differ in their underlying severity of illness and, 
hence, profitability. In Section IV, we describe our data, and in Section V, we present the results of our analyses of the effects of competition on cost. Section VI concludes and examines the implications of our work for the design of reimbursement strategies, for quality assessment, and for outcomes research.

\section{Background on Cost-Containment in California, 1983-1993}

Between 1983 and 1993, diverse cost-containment strategies were undertaken in California. They led to a widespread transition to prospective payment systems as well as intensified hospital market competition. ${ }^{3}$ Here, we discuss briefly major cost-containment strategies that were implemented over this period: the Medicare Prospective Payment System; selective provider contracting among California's Medicaid program, Medi-Cal, and health care providers; and the expansion of managed care arrangements.

\section{Medicare PPS}

Prospective payment systems certainly existed prior to the establishment of the Medicare PPS in 1983. Nevertheless, the scale and influence of Medicare made the shift from retrospective reimbursement on the basis of reasonable costs to PPS a change of fundamental importance for hospitals. With the establishment of PPS, reimbursement for nearly all hospitalizations under Medicare were made on the basis of prospectively fixed rates according to diagnosis-related groups. Each hospitalization is assigned a DRG based on principal diagnosis or the performance of a very limited number of particularly costly procedures (for example, coronary artery bypass graft surgery). Each DRG is assigned a fixed weight that reflects its relative cost of treatment with respect to a base rate. Because hospitals are paid a fixed amount per DRG based on the DRG weight, the classification system and aimed to create groups of patients as homogeneous as possible with respect to resource consumption. DRGs were also stratified with respect to age and the presence of complications.

After a phase-in period of four years, during which hospital reimbursement reflected a mix of national, regional, and facility-specific rates (Smith and Fottler 1985), hospitals were reimbursed for each case according the national average cost of treating a base case (with adjustments to reflect location and local wages), multiplied by the DRG 
weight (Davis et al. 1990). Thus, reimbursement under PPS was fully prospective from the onset, but the persistence of differences in payment rates based on historical local costs meant that the competitive aspects of PPS increased progressively over its phase-in.

\section{Medi-Cal Selective Contracting}

The same year that Medicare PPS was implemented, California enacted legislation authorizing the state Medicaid program, Medi-Cal, to negotiate contracts with health service providers for the care of Medi-Cal beneficiaries. This was done with the intent to promote price competition in the Medicaid market. Under this legislation, eligible, short-term, acute-care general hospitals were offered the opportunity to negotiate service provision contracts with Medi-Cal on the basis of fixed per-diem rates (Johns 1985). Failure to secure a contract meant that hospitals would not be reimbursed for care given to Medi-Cal patients except in cases of emergency (Langa 1992). Although the per-diem reimbursement established under this legislation did not result in a fully prospective payment system for Medi-Cal patients, the resulting declines in Medi-Cal reimbursement also intensified the competitive pressure on California hospitals during this period.

\section{Expansion of Managed Care}

During the 1980s, managed care spread rapidly throughout the United States, but particularly in California. By 1988, California ranked first in the nation in terms of its $\mathrm{HMO}$ enrollment rate, with roughly 28.5 percent of the state population ( 7.68 million individuals) belonging to an HMO (Johns 1989). This was more than double the national rate in 1987, when only 12.1 percent of the U.S. population was enrolled in an HMO (Davis et al. 1990), and even well above the national rate of 19.7 percent in 1994 (Institute of Medicine 1997). Likewise, the number of Preferred Provider Organizations (PPOs) in California grew 94 percent, from 34 PPOs in 1984 to 72 in 1988 (Johns 1989).

Some managed care payers adopted prospective payment systems for hospital care similar to Medicare PPS. However, the majority adopted other approaches to cost control, such as selective contracting, per diem reimbursement, and utilization review. These mechanisms did not necessarily provide any particular incentive to decrease expenditures for high-cost users relative to low-cost users (Gold et al. 1995). ${ }^{4}$ 
Nevertheless, many aspects of managed care served to further intensify competition in California during these years.

Indeed, the empirical evidence suggests that Medicare PPS, Medi-Cal selective contracting, and managed care arrangements all contributed to curbing cost growth. From 1967 to 1984, Medicare hospital care expenditures had been growing at an average annual rate of 16.5 percent; in the seven years immediately following PPS, growth fell to 7.3 percent (Davis and Burner 1995). Based on projections of Medicare expenditures, Russell and Manning (1989) estimated savings of $\$ 12$ to $\$ 18$ billion for 1990 under PPS. Medi-Cal selective contracting in California also appears to have been largely successful in raising the level of competition in hospital markets while simultaneously suppressing cost growth (Johns 1989, Robinson and Phibbs 1989, Melnick et al. 1992). The growth of managed care organizations also contributed to lower cost growth, both by delivering health care at lower costs due to lower service intensity (Manning et al. 1984) and by increasing competition in hospital markets (Melnick and Zwanziger 1995).

Thus, between 1983 and 1993, hospitals in California became increasingly subject to prospective payment systems as a result of Medicare PPS, and increased competition due to the effects of Medi-Cal selective contracting and the growth of managed care. In this context, economic theories of provider behavior under prospective reimbursement suggest incentives to decrease expenditures on high-cost patients while increasing expenditures on low-cost patients, as we explore below.

\section{Economic Theories of Provider Behavior Under Fixed-Rate Prospective Payment Systems}

Many cost-containment strategies rely on supply-side cost sharing to achieve cost-containment objectives. Whereas retrospective reimbursement systems largely insulate providers from increases in costs, providers under prospective payment systems are paid a fixed rate per unit of output that is defined in advance.

If the patient population is taken as given, such payment schemes that hold providers financially responsible for the marginal costs of treatment can create incentives to reduce provision of unnecessary services to patients. This is reflected by the common view of managed care as reducing services. What is less appreciated, however, is that when providers have to compete for patients, prospective payment systems also create a new distinction among patients, namely, a distinction between profitable and unprofitable patients, depending on their ex- 
pected costs relative to the level of prospective reimbursement (Newhouse 1989). Thus, when profit-maximizing hospitals under fixed-rate prospective reimbursement face a patient population of variable illness within a reimbursement category (such as a DRG), they may have incentives to provide excessive levels of care for the less ill and/or to choose and advertise quality of care or amenities that differentially attract profitable patients while avoiding unprofitable ones (Hornbrook and Rafferty 1982, Ellis and McGuire 1986, Dranove 1987, Luft and Miller 1988, Newhouse 1989, Hodgkin and McGuire 1994, Ellis 1998). ${ }^{5}$ When intensified competition decreases overall profit levels and increases the price responsiveness of patient volume, such strategies may become matters of institutional survival. Thus, as Ellis (1998) has shown, incentives to engage in patient selection and discrimination in quality provision are exacerbated under increased competition, a condition that has been realized in many U.S. hospital markets in recent years due to greater market penetration by managed care organizations (Ellis 1998, Dranove and White 1994).

The empirical implications of these theories is that, where providers are subject to fixed-rate prospective payment systems, declines in hospital cost growth will be concentrated at the top of the spending distribution. In other words, high-cost (unprofitable patients) will experience greater reductions in resource consumption relative to low-cost (profitable) patients. Furthermore, these effects will be magnified under competition.

To illustrate this, we develop the following model of choice of quality of care for patients with differing severity of illness ( $s$ ) given a prospective payment rate $(P)$. Specifically, we model the choice of quality of care for patient of severity $s$ at $\operatorname{cost} c\left(q_{s}\right)$. To capture the variation in costs of patients who differ in severity of illness, we allow the cost of providing basic care to depend also on severity $[c(s)]$. Thus, the total cost of caring for a patient of a given severity is $c(s)+c\left(q_{s}\right)$. The first component, $c(s)$, is nondiscretionary, whereas the second component, $c\left(q_{s}\right)$, is subject to choice depending on the desire of a hospital to provide additional quality. In other words, we model the profit from caring for a patient of a given severity level (s) under prospective payment as:

$\pi=P-c(s)-c\left(q_{s}\right)$

We assume that $c_{s}>0, c_{s s}>0$ and that, with respect to the cost of delivering discretionary quality, $c(0)=0, c_{q}>0$, and $c_{q q}>0$. To go from 
this patient-level profit to the profit earned from caring for the class of patient of severity $s$, we allow the demand for care by patients of severity $s$ when quality is $q_{s}$ to be $D\left(s, q_{s}\right)=D\left(q_{s}\right), D_{q_{s}}>0, D_{q_{s} q_{s}}<0$. The hospital chooses $q_{s}$ to maximize profit:

$$
\underset{\mathbf{q}_{\mathrm{s}}}{\operatorname{Max}} \pi=D\left(q_{s}\right)\left[P-c(s)-c\left(q_{s}\right)\right]
$$

Taking the derivative of equation (3.2) with respect to $q_{s}$ yields the first-order optimality condition that hospitals set the marginal revenue from additional quality equal to the marginal cost of providing that quality:

$\frac{d \pi}{d q_{s}}=D^{\prime}\left(q_{s}\right)\left[P-c(s)-c\left(q_{s}\right)\right]-D\left(q_{s}\right) c^{\prime}\left(q_{s}\right)=0$

Equation (3.3) implies:

$$
\frac{\left[P-c(s)-c\left(q_{s}\right)\right]}{c\left(q_{s}\right)}=\left(\frac{1}{\frac{D^{\prime}\left(q_{s}\right) q_{s}}{D\left(q_{s}\right)}}\right)\left(\frac{c^{\prime}\left(q_{s}\right) q_{s}}{c\left(q_{s}\right)}\right)=\frac{\varepsilon_{c, q_{s}}}{\varepsilon_{D, q_{s}}}
$$

Totally differentiating and checking second-order conditions demonstrates:

$$
\frac{d q_{s}}{d_{s}}=\frac{D^{\prime \prime}\left(q_{s}\right)\left(P-c(s)-c\left(q_{s}\right)\right]-2 D^{\prime}\left(q_{s}\right) c^{\prime}\left(q_{s}\right)-D\left(q_{s}\right) c^{\prime \prime}\left(q_{s}\right)}{D^{\prime}\left(q_{s}\right) c^{\prime}(s)}<0
$$

as long as $P-c(s) \geq 0$, and $q_{s}=0$ otherwise. Thus, discretionary quality falls with severity for all profitable patients and is set to zero for all unprofitable patients.

\section{Comparison to Retrospective Reimbursement}

Since one of the empirical comparisons we will make is between prospective reimbursement and retrospective reimbursement, it is useful to contrast this result with the result that would transpire under a retrospective reimbursement system, according to our model. In particular, instead of a fixed price $P$ that is independent of severity and quality, a retrospective reimbursement system may in general depend on both, for example, $P\left(s, q_{s}\right)$. Under some circumstances, this makes the comparison between prospective and retrospective reimbursement easy; in others, it is more difficult. To illustrate this, assume $P\left(s, q_{s}\right)$ takes the general form $P\left(s, q_{s}\right)=P_{0}+P_{s} c(s)+P_{q_{s}} c\left(q_{s}\right)$, where $P_{0}, P_{s}$, and $P_{q_{s}}$ are the 
rates at which hospitals are reimbursed for, respectively, the basic admission (as in prospective payment), expenditures on severity-related costs, and expenditures on discretionary dimensions of quality (for example, amenities). In general, the latter two categories may be hard to distinguish in practice, but the distinction is worth making to reflect the idea that there may be some expenditures that may not be covered fully under a retrospective reimbursement system but are nevertheless desired by hospitals to attract patients. ${ }^{6}$ For our purposes, the most straightforward case is when reimbursement provides a fixed amount of profit per admission by providing a lump-sum profit $(K)$ per admission and exactly reimburses severity-related costs while not covering quality-related costs. In that case, $P_{0}=K>0, P_{s}=1$, and $P_{q_{s}}=0$. Equation (3.4) becomes

$\frac{\left[K-c\left(q_{s}\right)\right]}{c\left(q_{s}\right)}=\frac{\varepsilon_{c, q_{s}}}{\varepsilon_{D, q_{s}}}$

and quality is independent of $s$. In this case, the shift to prospective payment would be expected to decrease spending for more expensive patients relative to less expensive ones.

Perhaps even more relevant is the case in which retrospective reimbursement provides no fixed profit per admission but instead offers a markup over costs for severity-related costs, for example, $P_{0}=0, P_{s}>$ 1 , and $P_{q_{s}}=0$. Here equation (3.4) becomes

$\frac{\left[P_{s} c(s)-c(s)-c\left(q_{s}\right)\right.}{c\left(q_{s}\right)}=\frac{\varepsilon_{c, q_{s}}}{\varepsilon_{D, q_{s}}} \quad$ and $\quad \frac{d q_{s}}{d s}>0$

Thus, with $P_{s}>1$, hospitals make more profit on more expensive patients and therefore will spend more on quality for the more expensive patients. Again, the switch to prospective payment will lead to a reduction in spending among the sicker patients.

Finally, it is also worth considering a system in which no fixed profit per admission is given but in which all costs related to both severity and quality are reimbursed retrospectively with a markup. Some might consider this most like the retrospective reimbursement system as it was applied prior to prospective payment. In this case, $P_{0}=0$, and $P_{s}=$ $P_{q_{s}}>1$. Equation (3.4) now becomes:

$$
\frac{\left[P_{s} c(s)+P_{q_{s}} c\left(q_{s}\right)-c(s)-\left(q_{s}\right)\right]}{c\left(q_{s}\right)}=\frac{\left[\left(P_{s}-1\right)\left(c(s)+c\left(q_{s}\right)\right)\right]}{c\left(q_{s}\right)}=\frac{\varepsilon_{c, q_{s}}}{\varepsilon_{D, q_{s}}}
$$

and again $\quad \frac{d q_{s}}{d s}>0$ 
This seems to suggest that quality would rise with severity, but this conclusion would be misleading because full retrospective reimbursements for amenities provide no incentives for hospitals to limit expenditures on amenities. Hence, the second-order conditions actually imply that the optimal quality hospitals should provide is infinite quality for all patients. Thus, there must be some other constraint on the reimbursement of discretionary care, which seems most likely to be a combination of the possibility of doing harm to the patient (and associated risk of liability) and whatever limits are placed by the payer. Whichever the case, it is not possible to predict how prospective payment will affect discretionary expenditures on low- and high-cost patients.

To summarize, except in the case where discretionary expenditures are not limited by economic incentives, there appears to be a fairly broad set of assumptions under which prospective payment would be expected to reduce expenditures selectively for the most expensive patients relative to retrospective reimbursement.

\section{Effects of Competition}

Equation (3.4) implies that the ratio of profit to cost for quality falls with increasing elasticity of demand with respect to quality so that, accordingly, quality rises with increasing elasticity of demand with respect to quality. Since the out-of-pocket cost of a hospitalization to a Medicare patient is independent of the hospital she or he chooses, it seems likely that competitive pressures will make this elasticity quite large, although such competitive forces will surely be limited by geographic factors in areas where there are few hospitals so that patient options are limited due to high search and transportation costs, and where changes in quality are more likely to be coordinated (Bain 1951, Stigler 1968, White 1972, Tirole 1988). ${ }^{7}$ Rearranging equation (3.4) and solving for $c\left(q_{s}\right)$ yields:

$c\left(q_{s}\right)=\frac{\varepsilon_{D, q_{s}}}{\left(\varepsilon_{c, q_{s}}+\varepsilon_{D, q_{s}}\right)}[P-c(s)]$

Quality is set to a minimum for unprofitable patients, so equation (3.6) applies where patients are profitable (thus, the numerator is positive), and quality for profitable patients rises with the degree of competition. As indicated above, quality falls with increasing severity, and here the rate at which expenditures on quality fall with increasing severity rises with increasing elasticity of demand with respect to quality 
(for example, competition), so that the positive effect of competition on costs is dampened for more costly patients. Thus, an increasingly competitive environment under prospective payment has the effect of raising quality most for the least costly patients. Because competition under prospective payment may also increase efficiency, this may not result in an absolute increase in costs but should at least lessen cost decreases for the least expensive patients relative to the most costly patients, for whom the clear incentive is to reduce expenditures if possible because they are not profitable. Indeed, in the limit, as the elasticity of demand with respect to quality approaches infinity, expenditures on quality fall dollar for dollar with increasing severity of illness because all profits are competed away at each level of severity.

\section{Data and Methods}

\section{Data Description: California Hospital Cost and Financial Data}

We use the 1983 and 1993 hospital discharge and financial data released for public use by the California Office of Statewide Health Planning and Development (OSHPD). The financial data is described in detail below. The discharge data cover all inpatient discharges from every licensed, nonfederal hospital in California, as well as discharges from some specialized facilities such as psychiatric hospitals and rehabilitation and nursing facilities. Data elements available for each patient abstract in the public-use files include facility identifiers, patient age, zip code of patient residence, expected source of payment, total charges incurred by patients during their hospitalization episode, and patient DRG classification. Additional data for calculating per-capita spending and utilization rates comes from the U.S. Bureau of the Census Intercensal Population Estimates by Age, Sex, and Race (U.S. Department of Commerce, Bureau of the Census 1993, 1998).

We limit our analysis to all California state residents (identified by zip code) discharged from acute-care facilities for which data on total hospital charges are available. Certain institutions, many of which are managed-care facilities such as Kaiser hospitals, do not report total charges on their discharge abstracts because they are exempt from standard OSHPD accounting procedures. As a convention, patients discharged from these hospitals have zero charges recorded in their abstracts, although true costs of treatment were nonzero. Since total hospital charges for these patients cannot be ascertained, they are excluded from our analyses. ${ }^{8}$ 
To calculate costs, we begin with charge data that we convert to 1993 constant dollars using the general Consumer Price Index and then to costs using annual, institution-specific ratios of costs-to-charges (RCCs). These RCCs are calculated using the OSHPD Financial Disclosure Data, which report facility-level data on total operating expenses, gross patient revenue, and other nonoperating revenue. Because other nonoperating revenue consists of revenue from hospital enterprises such as the outpatient pharmacy and gift shop, we follow the approach recommended by the Office of Statewide Health Planning and Development (1993) in calculating RCCs:

$\mathrm{RCC}=\frac{\text { total operating expenses }- \text { other nonoperating revenue }}{\text { gross patient revenue }}$

RCCs are commonly used to estimate costs from charges, but OSHPD data do not permit disaggregation of inpatient charges into its component departments and services. Thus, institution-level RCCs must be used, which is an important limitation because they cannot reflect discrepancies between costs and charges that arise due to internal cross-subsidization across departments and services within a facility. Nevertheless, facility-level RCCs can adjust for certain discrepancies between costs and charges [for example, whether or not a facility treats a large proportion of charity cases (Finkler 1982)] and have been found to perform somewhat better than charges as proxies for costs (Newhouse, Cretin, and Witsberger 1989; Schwartz, Young, and Siegrist 1995). While this suggests some justification for analyzing RCC-adjusted charges rather than raw charges, the most compelling reasons during the period we study is the growing inflation of charge rates to full-paying patients and the concomitant use of rebates for managed care contracts. The upshot of this is that charge growth based on charges may overstate real cost increases (Dranove, Shanley, and White 1991) if managed care rebates are not taken into consideration. The advantage of using RCCs in this case is that increase in gross patient charges that are offset by increases in rebates will result in a decrease in the RCC as calculated above. As a result, estimates of costs based on patient-level charges and RCCs are not inflated inappropriately by the use of rebates.

In addition to the effects of discrepancies between costs and charges on aggregate charge growth, it is also important to consider the possibility that such discrepancies could have effects on costs across the spending distribution if they do not apply uniformly across it. Indeed, 
it is possible that the discrepancy between costs and charges could vary across the spending distribution. For example, if the markup on low-cost services and departments exceeds the markup on high-cost services and departments, then the actual distribution of costs across patients will be more concentrated than suggested by the distribution of charges. Although it is not clear that this is the case, it is possible that such markups may change over time, for example, if competition is particularly intense in high-cost services so that cost containment differentially reduces charges in these areas. If so, it is possible that an analysis of hospital charges may overstate costs at the bottom of the distribution in later years and understate costs at the top of the cost distribution.

Although this would lead to patterns in hospital costs similar to those we find, we do not believe that internal cross-subsidization drives our results because we study a period in which all payers were tightening their reimbursement policies, thereby imposing a constraint on the extent to which hospitals could shift costs to other payers and departments. Indirect support for this comes from Dranove and White (1998), who studied the responses of California hospitals to Medicaid fee reductions between 1983 and 1992 and found significant reductions in levels of services provided to all patients, and Medicaid patients in particular, but no evidence of cost shifting. The ideal data to test this would allow us to assess whether rebates were more likely for sicker patients within a hospital, but the available data do not permit this disaggregated analysis because rebates are not made on a patient-level basis. As an alternative check, however, we examined whether hospitals in the OSHPD data that care for sicker patients (as measured by either greater average age, length of stay, or in-hospital mortality) were likely to give greater rebates to payers as a percentage of net revenue. Our results suggest no evidence of any significant relationship or change in relationship over time between rebates and patient age or length of stay, but they do suggest a positive relationship between rebates and mortality in the first six years we study and that this relationship is eliminated by the end of the period. While this latter result could suggest an artificial inflation of costs for the sickest patients initially that is later eliminated, the effect is not large. Thus, while there are possible reasons to be concerned that changes in the relationship between costs and charges across patients who differ in severity of illness could influence our results, we cannot find evidence of any changes in such relationships. 


\section{Limitations of Cost and Financial Data}

Several data and analytic limitations should be recognized at the outset. First, the 1983-1993 period was one during which hospital accounting and reimbursement systems were in flux. Hospitals are instructed by OSHPD to report the total charges incurred during a patient's hospitalization according to the facility's full-established rates prior to any prepayment deductions. At a minimum, hospitals are to include all charges associated with daily hospital services, ancillary services, and patient care services in calculations of total inpatient charges per discharge. Physician fees are omitted. Due to the volume of discharges processed, OSHPD does not conduct comprehensive accounting checks; hence, the reliability of reported data on charges is unknown. Nevertheless, the OSHPD charge data has been widely used by several researchers, for example, Robinson and Phibbs 1989, Stafford 1990, Langa 1992, Langa and Sussman 1993, Melnick and Zwanziger 1995, and Dranove and White 1998.

Another issue is related to our lack of data concerning charges associated with outpatient care and forms of postdischarge care. Since the introduction of PPS and managed care, many have speculated that any decline in hospital spending may be offset by growth in other sectors such as ambulatory and long-term care. Since we are unable to account for cost shifting across sites of delivery, our finding that growth in hospital charges fell among high-cost admissions does not imply that the total cost of treatment among high-cost admissions also fell because these patients may be heavy consumers of postdischarge health care resources. However, we found no tendency for differential cost reduction among high-cost admissions with increasing competition in diagnoses with high or increasing levels of discharge to skilled nursing facilities. Even if such a pattern were found, it could be interpreted as providing insight into a mechanism by which quality discrimination was accomplished.

A final point concerns the period over which we have data to analyze. The earliest data we have date back to 1983, the year in which Medicare's DRG-based Prospective Payment System was implemented and legislation authorizing selective contracting between Medi-Cal and service providers took effect. Also, throughout the 1983-1993 period, HMOs and various other managed care organizations emerged and proliferated. Because we do not have comparable data that antedate these major changes and because important changes were 
happening in the reimbursement strategies for younger persons at the same time, it is important to be cautious in drawing a causal connection between these specific policies and observed trends in charge growth. On the other hand, because Medicare PPS, Medi-Cal, and managed care all rely on different approaches to achieve cost containment, we can, to interpret our empirical findings, borrow insights from the theoretical models of provider responses to alternative reimbursement systems described above.

\section{Measures of Competition}

A large body of literature attempts to identify the appropriate measures of markets and competition in health care. Key debates in this literature concern methods for defining health care markets (for example, geopolitical boundaries, patient flow, or economic measures such as cross-price elasticities), the appropriate level of analysis (for example, facility level, medical service level, or patient level), and mathematical measures for computing market concentration (for example, the Hirschman-Herfindahl Index, spatial density of competitors, or entropy). ${ }^{9}$ Although these approaches may differ in their theoretical appeal, both in general and in individual applications, expediency has often been the operative criterion by which methodology has been chosen. By far, the most common approach has been to define markets on the basis of geopolitical boundaries (counties, Metropolitan Statistical Areas (MSAs), and/or Health Service Areas (HSAs) and to measure concentration using the Hirschman-Herfindahl Index (HHI) for total admissions at the county level. ${ }^{10}$ In the analyses reported here, we follow the same approach. Several studies have examined the robustness of the empirical findings in hospital markets compared to alternative methods of market delineation and concentration measurement. Some have found that results are not robust compared to methods of market definition (see, for example, Dranove, Shanley, and Simon 1992; Sohn 1996; Kessler and McClellan 1999). Consequently, future plans for our research include replicating our analyses using alternative measures of competition.

\section{Analytic Plan}

To analyze the effects of competition across the distribution of health care expenditures, we include measures of competition in quantile re- 
gressions of cost for patients above and below age 65, and before the implementation of PPS in 1983 and after, in 1993. Our basic hypothesis is that competition under PPS will exert a downward pressure on costs among the most expensive elderly patients in 1993 relative to its effects among the less expensive elderly in 1993, relative to the expensive elderly in 1983, and relative to its effects among the young. To select the most appropriate comparison group among the young, we focus on persons age 55-64, though our results are not substantially different when we include persons age 5-54. Since our theory does not specify a specific measure of concentration, and since we have no reason to suspect a linear relationship between any particular measure of concentration and costs, we define a set of indicator variables to categorize counties in terms of their competitiveness based on the HHI ("less competitive" $\mathrm{HHI}>0.20$, "moderately competitive" $0.20 \geq \mathrm{HHI}>$ 0.10 , "competitive" $0.10 \geq \mathrm{HHI}>0.05$, and "very competitive" $\mathrm{HHI} \leq$ 0.05). We also control for payer (Medicare, Medi-Cal, other nonprivate, and private), as well as various market-level and hospital characteristics. The market-level characteristics are log physicians per capita, log HMO enrollment rate, log county population, and log income per capita. Hospital-level characteristics in our model are ownership status (for-profit versus nonprofit), teaching status (teaching hospital versus nonteaching hospital), number of licensed beds, and total number of discharges per year. In our basic specification, we do not control for patient characteristics such as age or comorbidity because PPS does not base much, if any, of its reimbursement rate on those factors. As a result, selectively caring for patients who are younger or have fewer comorbidities may be a mechanism by which hospitals respond to PPS and limit costs. In other words, controlling for age and comorbidity could mask the effect we aim to identify. In alternative specifications, we also include patient age and the number of secondary diagnoses, but find little change in our overall results.

We limit our analyses to the twelve largest DRGs by volume of discharges, more specifically, those DRGs with at least 10,000 discharges over the age of 4 in 1983 and 1994 combined. An important concern in this analysis relates to the incentives under Medicare PPS for hospitals to engage in "DRG creep," that is, the practice of progressively upcoding patients into DRGs with a higher reimbursement rate for a given condition (Carter, Newhouse, and Relles 1990). As a result of DRG creep, changes in charges within each stratified DRG may reflect trends in coding and classification rather than changes in service provi- 
sion. To address this concern, we aggregated DRGs for the same procedure and/or condition that are stratified for severity in calculating utilization rates and growth in charges. ${ }^{11}$

\section{Adjustments for Changes in Discharge Rates}

To know how to interpret changes in the effects of competition at different points in the spending distribution over time, and to generate meaningful estimates of cost growth over time at different points in the spending distribution, it is important to consider the dramatic decline in admission rates in California over this period because a given position in the spending distribution may reflect a different degree of severity in different years. The California data show that per-capita hospital discharge rates declined steadily from 112 discharges per 1,000 total population in 1983 to 69 discharges per 1,000 total population by 1993. The decline in California's discharge rates is consistent with national utilization trends, which began slowing in the 1970s but declined even further since the 1980s. Much of the decline has been attributed to more widespread use of utilization control mechanisms by Medicare, state Medicaid programs, managed care, and other third-party payers. These controls include peer-review organizations, physician gatekeepers, and precertification requirements employed by Medicare and other third-party payers. In California especially, declining rates of discharges may also reflect the expansion of HMO enrollment and the shift of many services to outpatient settings.

Assuming stable population morbidity from year to year, a falling admission rate implies that in each successive year, a smaller proportion of episodes of illness result in hospitalization. If one were to rank all admissions in order of increasing severity of illness, it would be reasonable to assume that, given the nature of utilization control measures, the distribution would tend to be truncated from the left, leaving the least severely ill patients denied hospital admission. Hence, not only does the proportion of the population experiencing hospitalization shrink over time, but the average severity level of the hospitalized population would also be expected to increase because there are fewer "healthy" admissions to dilute the spending distribution.

Figure 3.1 illustrates how shifts in utilization rates can complicate intertemporal comparisons of expenditures at specific locations within the population spending distribution. The $x$ axis plots the percentage of the population ranked in order of increasing severity of illness. The $y$ 


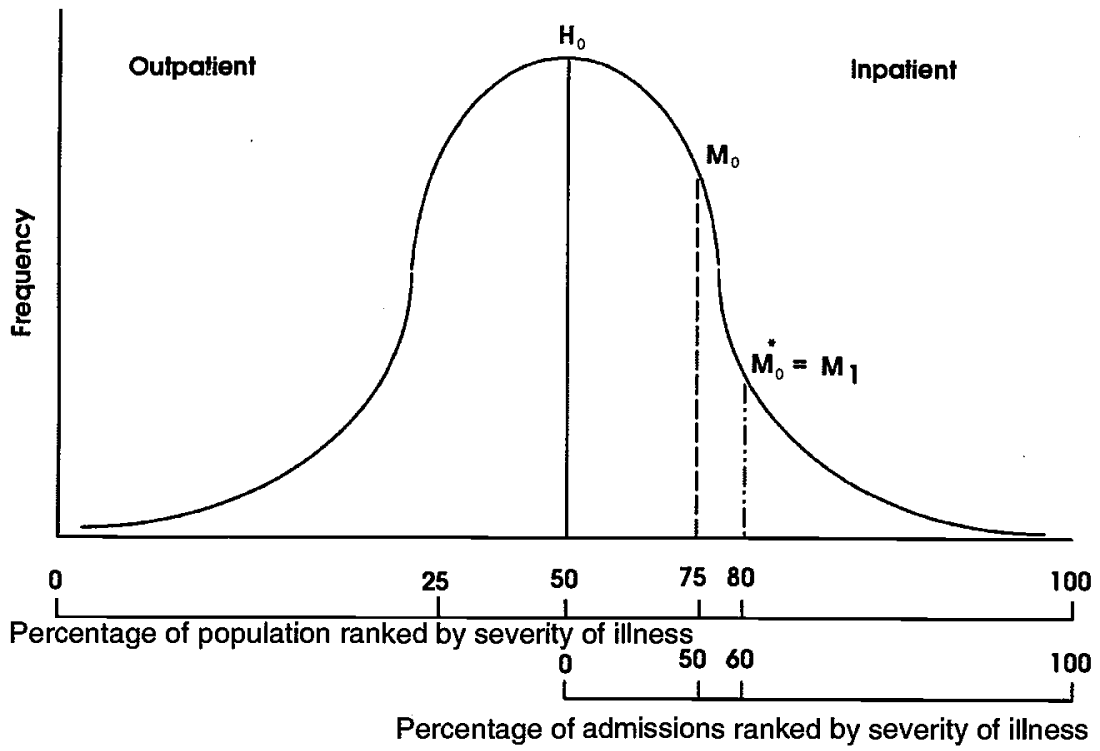

(a) Discharge distribution in year 0

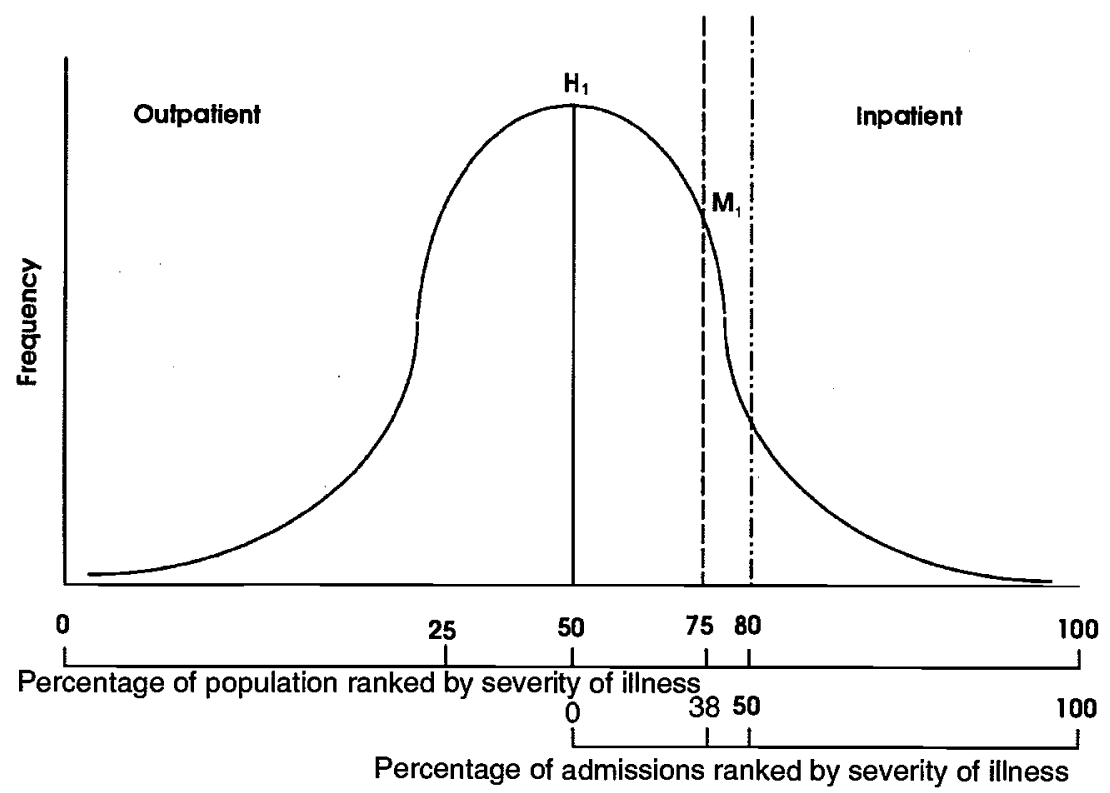

(b) Discharge distribution in year 1

Figure 3.1

Intertemporal comparisons of percentile locations in the spending distribution, adjusting for changes in hospital utilization rates 
axis plots the frequency or number of individuals at each severity level. The curves in figure 3.1(a) and 3.1(b) depict the distribution of illness in a given population, which we assume to be stable, at two time points: year 0 and year $1 . H_{0}$ and $H_{1}$ represent the discharge rates in year 0 and year 1 , respectively. In this hypothetical population, the top 50 percent of the population ranked in terms of morbidity were hospitalized in year 0 . In year 1 , the admission rate fell to 40 percent.

Suppose we wish to compare the effects on median hospital charges between year 0 and year 1 . In year 0 , the median discharge $\left(M_{0}\right)$ was the patient at the 75th percentile of the disease distribution. In year 1, the median discharge $\left(M_{1}\right)$ was at the 80 th percentile of the disease distribution. Because of the falling discharge rate between year 1 and year 2, these two discharges are not directly comparable. This is seen in figure 3.2 by the dotted line that traces $M_{0}$ down to the disease distribution in year 1 , and by the dotted line that traces $M_{1}$ above to the disease distribution in year 0 . Thus, the median discharge in year 0 was less ill than the median discharge in year 1 . Without taking into account falling discharge rates, a simple comparison between the median hospitalizations in year 0 and year 1 will compare patients that differ in their severity of illness.

To address this concern due to falling admission rates, we also performed all our analyses based on adjusted percentiles in which we aim to compare persons with comparable levels of severity of illness. Therefore, we examine growth rates or the effects of competition at adjusted percentiles wherever discharge rates fell between two time points, according to the following formula:

$P_{0}=\frac{\left(H_{0}-\left[H_{1} \times\left(1-P_{1}\right)\right]\right)}{H_{0}} \times 100$

where $P_{0}$ is the adjusted percentile in year $0, P_{1}$ is the percentile in the later time period (year 1), and $H_{0}$ and $H_{1}$ are the discharge rates in the two corresponding years. For example; to compare costs at the median of the spending distribution of the hypothetical population, we should compare the median discharge in year 1 to the discharge at the 60th percentile of discharges in year 0 because:

$P_{0}=\frac{(50-[40 \times(0.5)])}{50} \times 100=60$

We use this approach directly to calculate growth rates at different percentiles in the spending distribution. To analyze the effects of competi- 

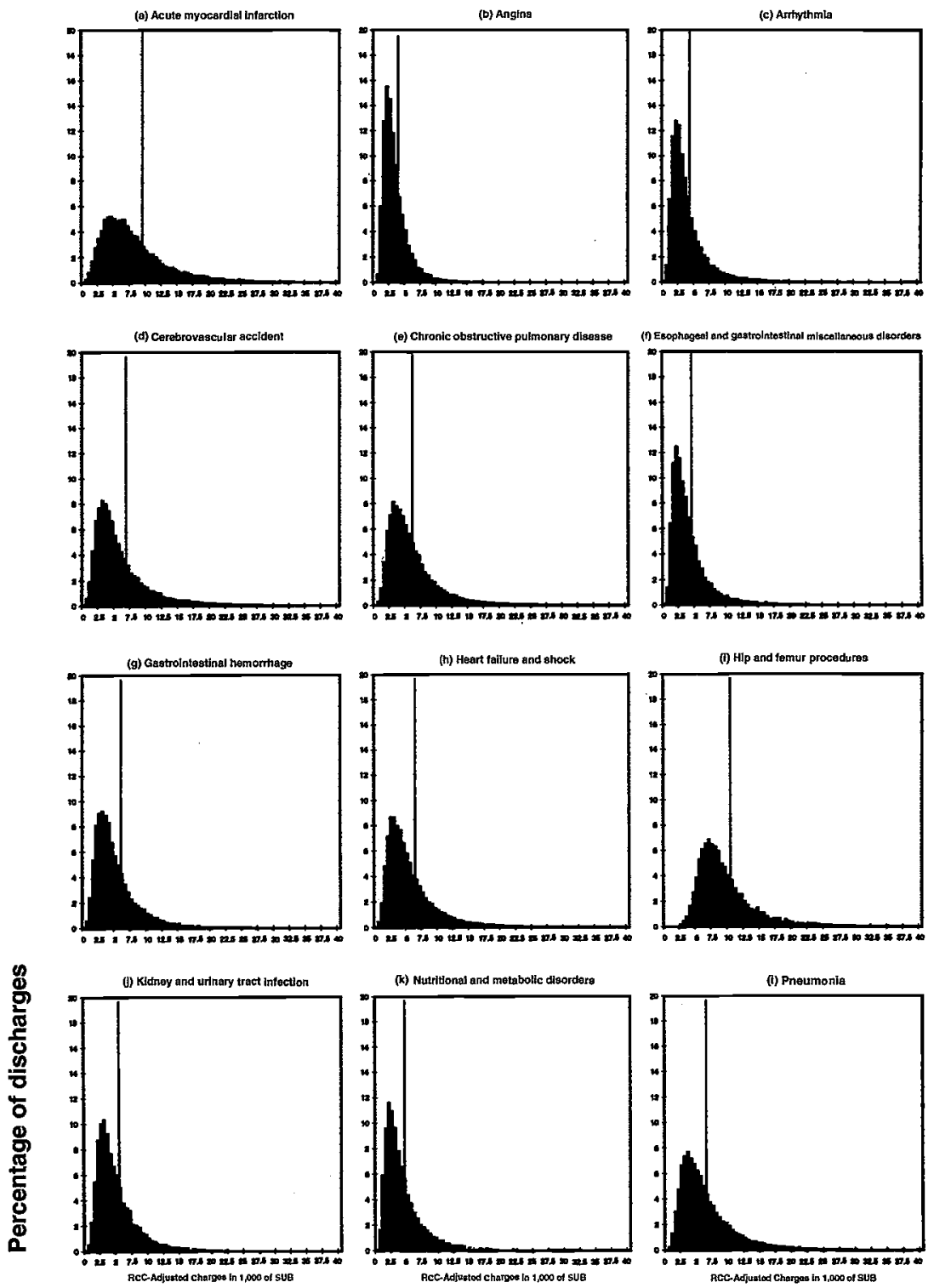

RCC-adjusted charges in thousands of U.S. dollars

Figure $3.2(a-1)$

The distribution of RCC-adjusted charges in DRG in 1993: age 65+ 
tion, we implement this adjustment by performing our regression analyses using the same number of observations drawn from the top of the distribution of the 1983 data as we have in the 1993 data.

Our method of adjustment exploits the fact that discharges fell over time and the fact that utilization control mechanisms typically raised the threshold of illness severity for hospital admission. This raises several potential problems. One is that in DRGs where discharge rates rise over time, it is not clear whether expanded services were extended to the less severely ill, or if improvements in technology and medical management enabled treatment of a greater number of the severely ill who would otherwise have remained untreated. Thus, in analyzing spending growth for the few DRGs where admission rates rose, we use all the observations from 1983 and analyze only unadjusted percentiles.

Probably more important is the possibility that reductions in admission did not come uniformly from the left tail of the distribution during this period. In an extreme example, suppose that, although we assumed that the reduction of 43 admissions per 1,000 population between 1983 and 1993 came from the left of the distribution (the "healthy" side), the reductions actually came entirely from the left side of the distribution. This might happen, for example, if the 43 fewer admissions in 1993 were terminally ill individuals who had been shifted into hospices but who would have died in hospitals at high cost in 1983. The top of the 1993 distribution would then be expected to have a lower average severity of illness level compared to the top of the 1983 distribution-the opposite of our assumption. This implies that an unadjusted comparison would understate growth, and that our adjustment procedure would further exacerbate this. Fortunately, for the diagnoses we examine, we believe that most of the reductions in admissions are due to the movement of less severely ill patients to the outpatient setting. This is supported by the observation that the greatest declines in admission rates in our sample were among admissions for esophageal and gastrointestinal disorders, which likely results from a movement toward treatment of the least severely ill patients in an ambulatory setting. It is also supported by additional analyses we performed showing that the degree of comorbidity of patients in these DRGs increased over our sample period. ${ }^{12}$ Nevertheless, we also examined the robustness of our findings under the assumption that the reduction in admissions is distributed evenly across 
the spending distribution by examining growth rates at the unadjusted percentiles.

\section{Results}

\section{Distribution of RCC-Adjusted Charges by DRG: 1983 and 1993}

Tables 3.1 and 3.2 show the number of cases and the distribution of costs in 1983 and 1993 for the twelve DRGs we examine. As figure 3.2 shows clearly, the distribution of costs in every DRG is highly skewed to the right, with about two-thirds of all admissions having costs below the mean (tables 3.1 and 3.2). This lays out the basic incentives implicit in PPS: that the majority of patients are profitable, while a minority are unprofitable but potentially responsible for large losses.

\section{Growth of RCC-Adjusted Charges by DRG: 1983 and 1993}

Table 3.3 shows the growth of costs from 1983 to 1993 at unadjusted and adjusted percentiles for persons older than age 65. Although there are few exceptions, the vast majority of the unadjusted and adjusted growth rates clearly show falling growth with increasing position in the spending distribution, as predicted by the theoretical predictions of the effects of prospective payment on costs.

Table 3.4 repeats these analyses for persons age 55-64. While the pattern is not as strong in several diagnoses as for those persons age 65 and older, there is still a clear trend for falling growth with increasing position in the spending distribution. This is not predicted by the theoretical model, and we will discuss possible reasons for this anomaly later.

\section{Effects of Competition on Hospital Expenditures: 1983 and 1993}

For the sake of parsimony, we present the full results of quantile regression analyses examining the effects of competition on cost at selected points in the distribution for one DRG only-acute myocardial infarction (AMI). The rest of the results are summarized in a separate table. Table 3.5 reports the quantile regression results for AMI admissions among persons age 65 and older in 1983 and 1993. table 3.6 reports results of parallel analyses for persons in the 55-64 age group. Table 3.7 reports the coefficients on the competition variables from the quantile 


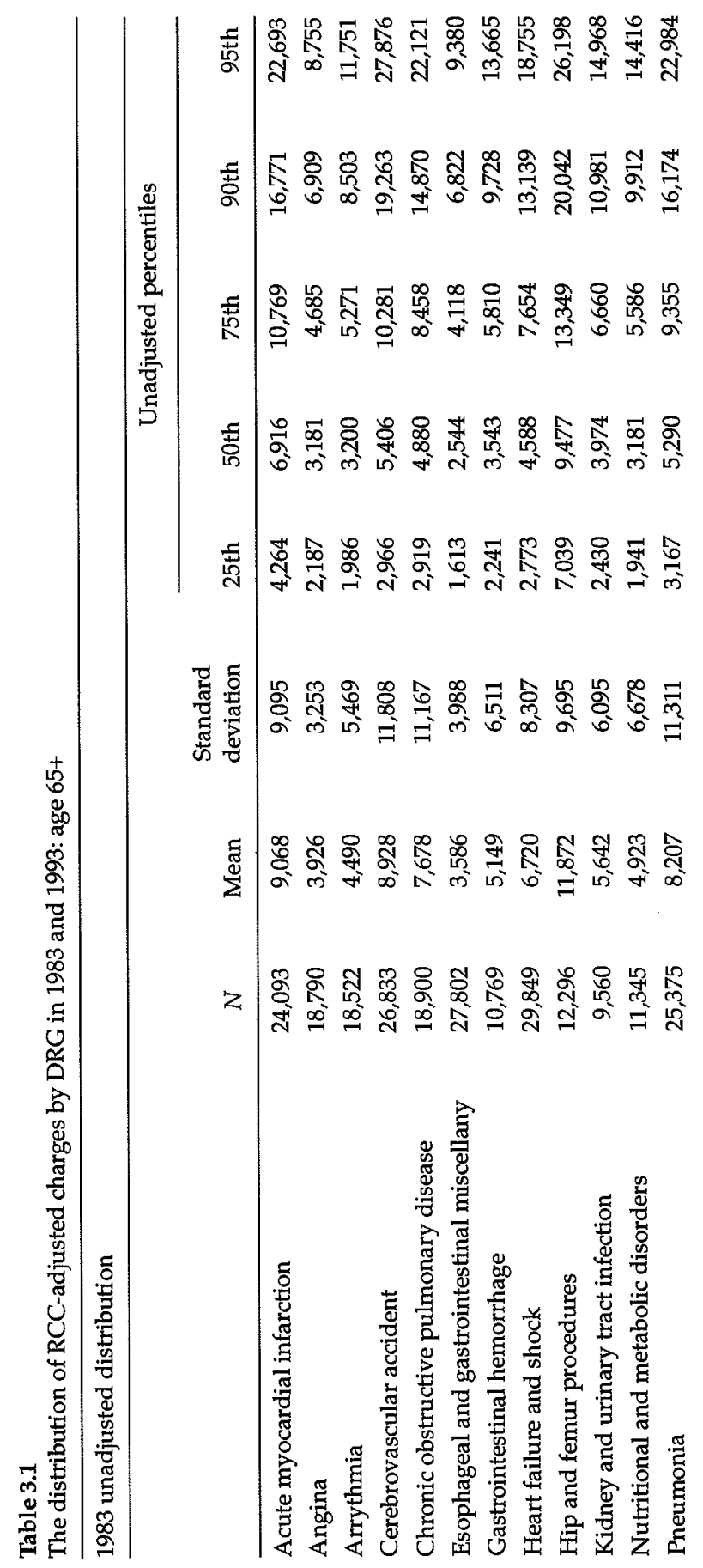




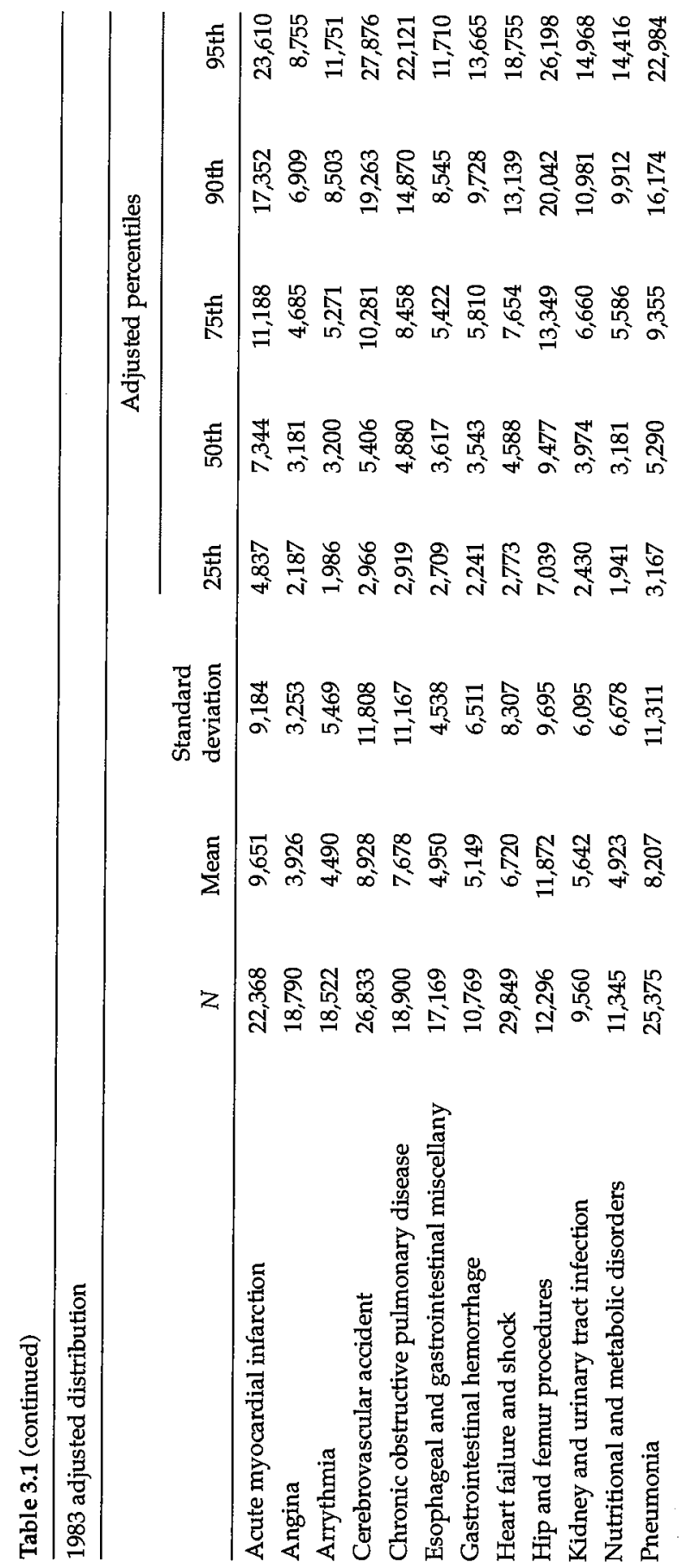




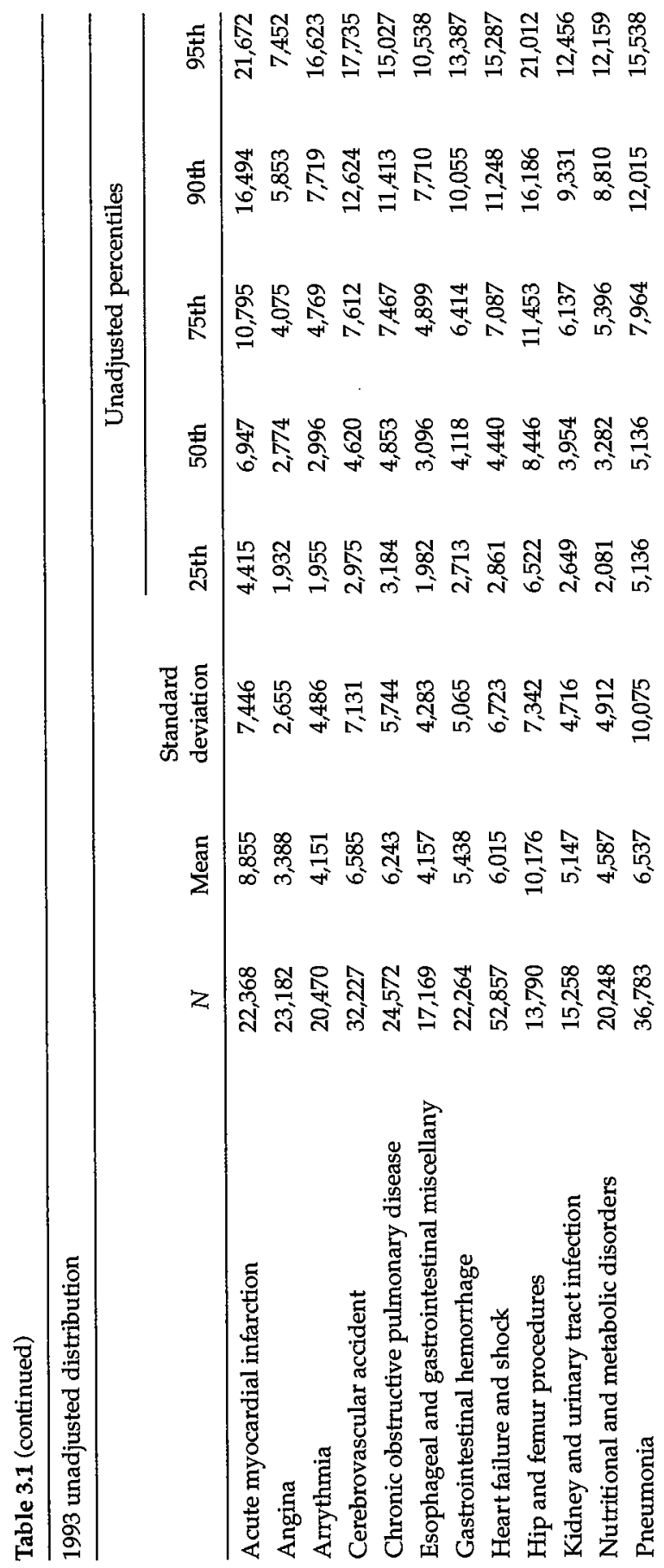




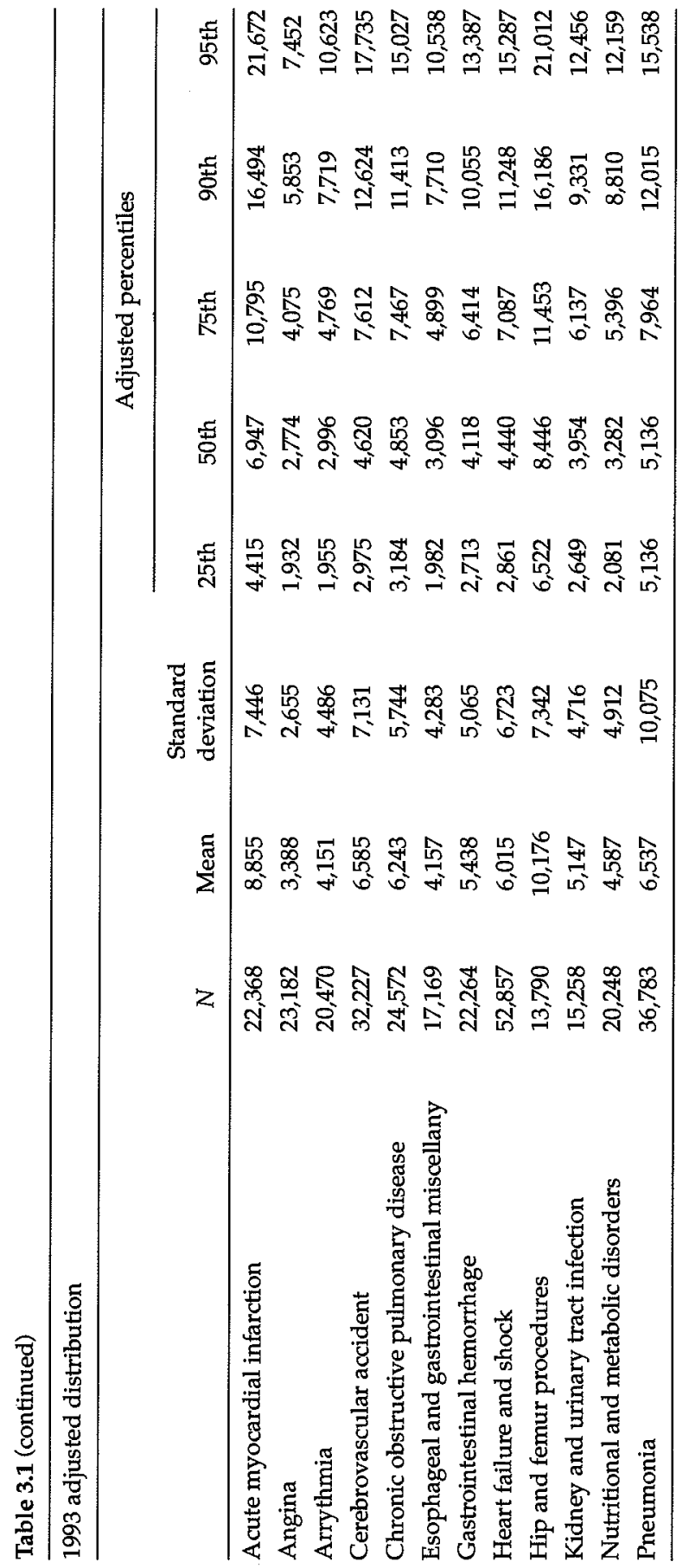




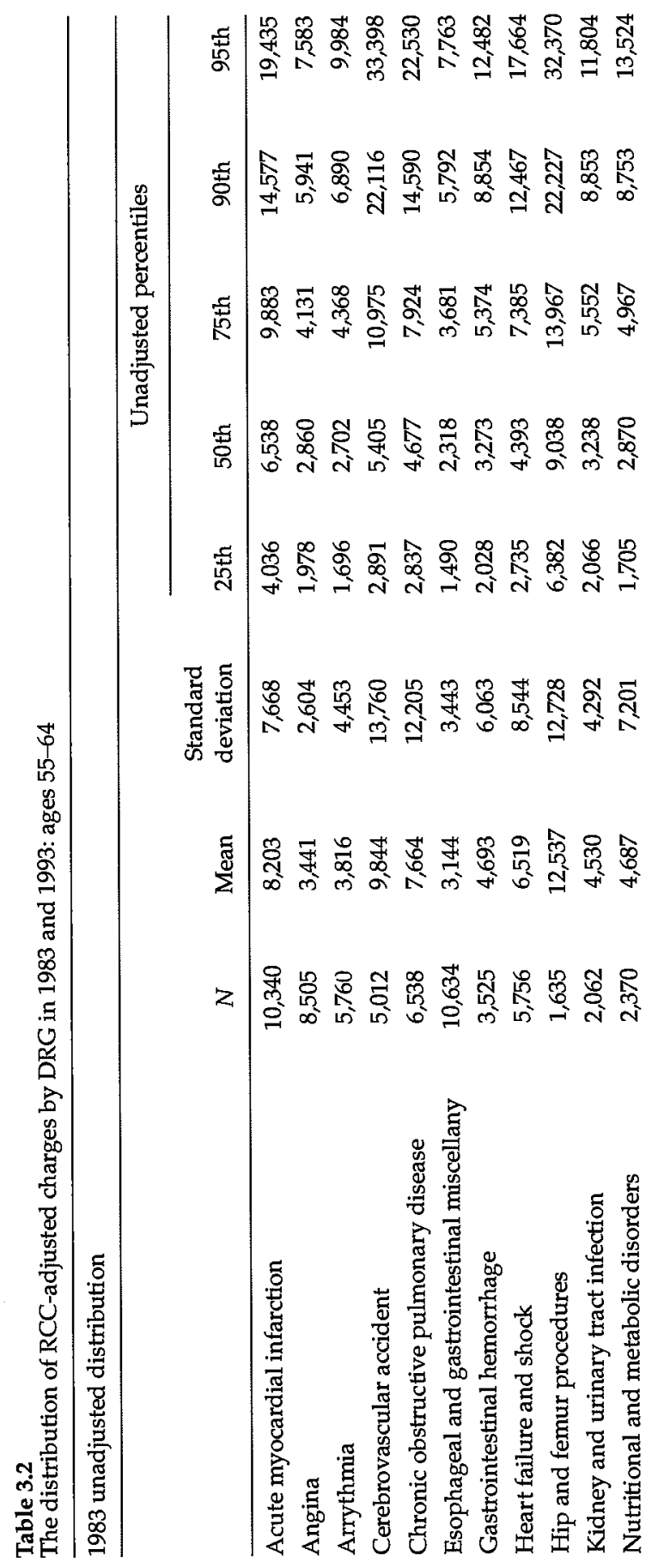




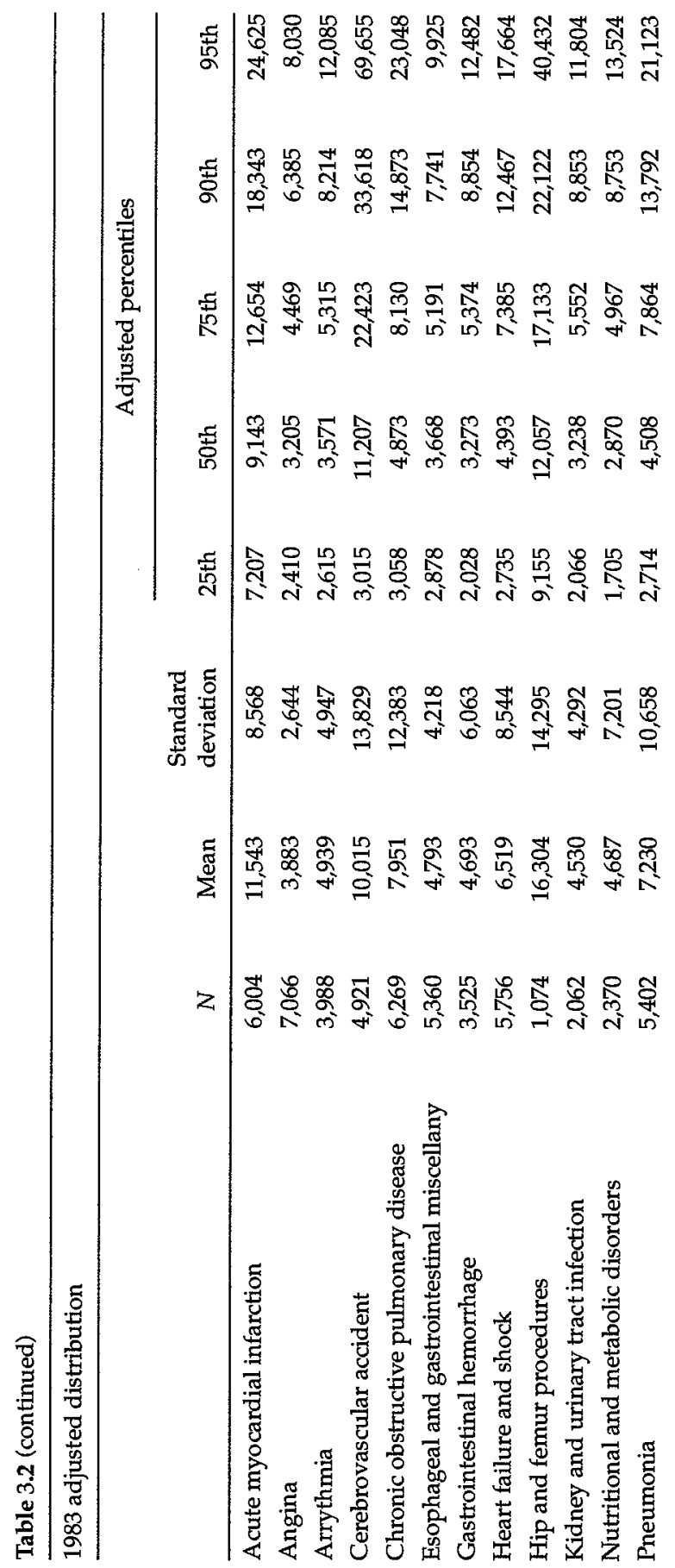




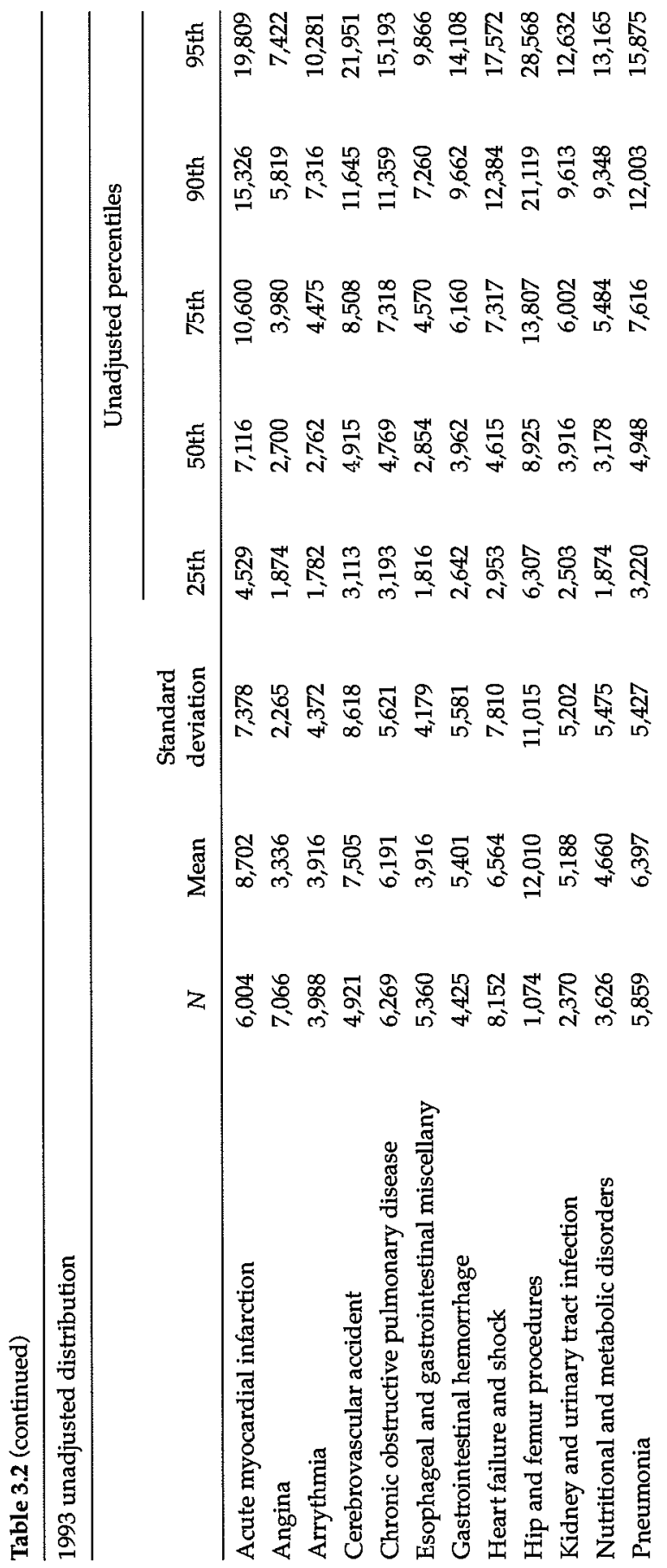




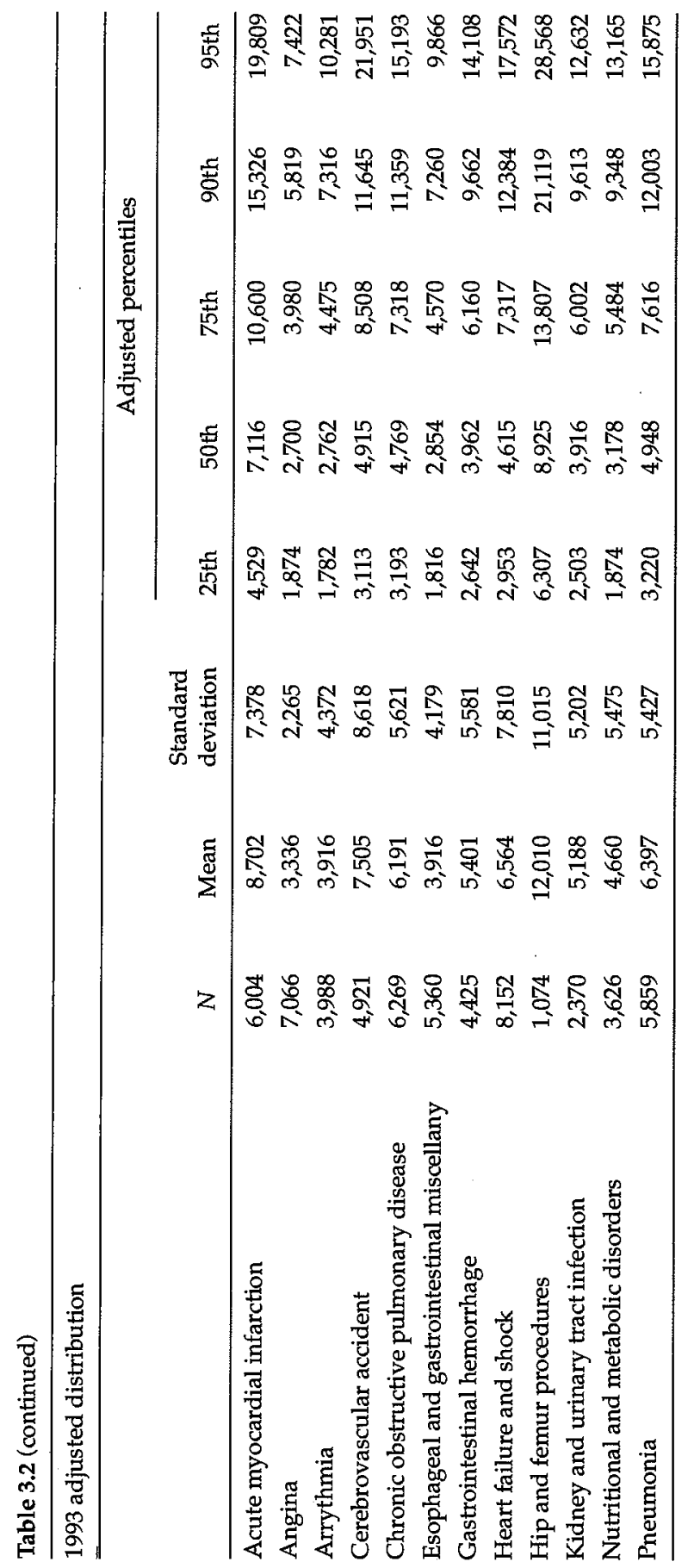




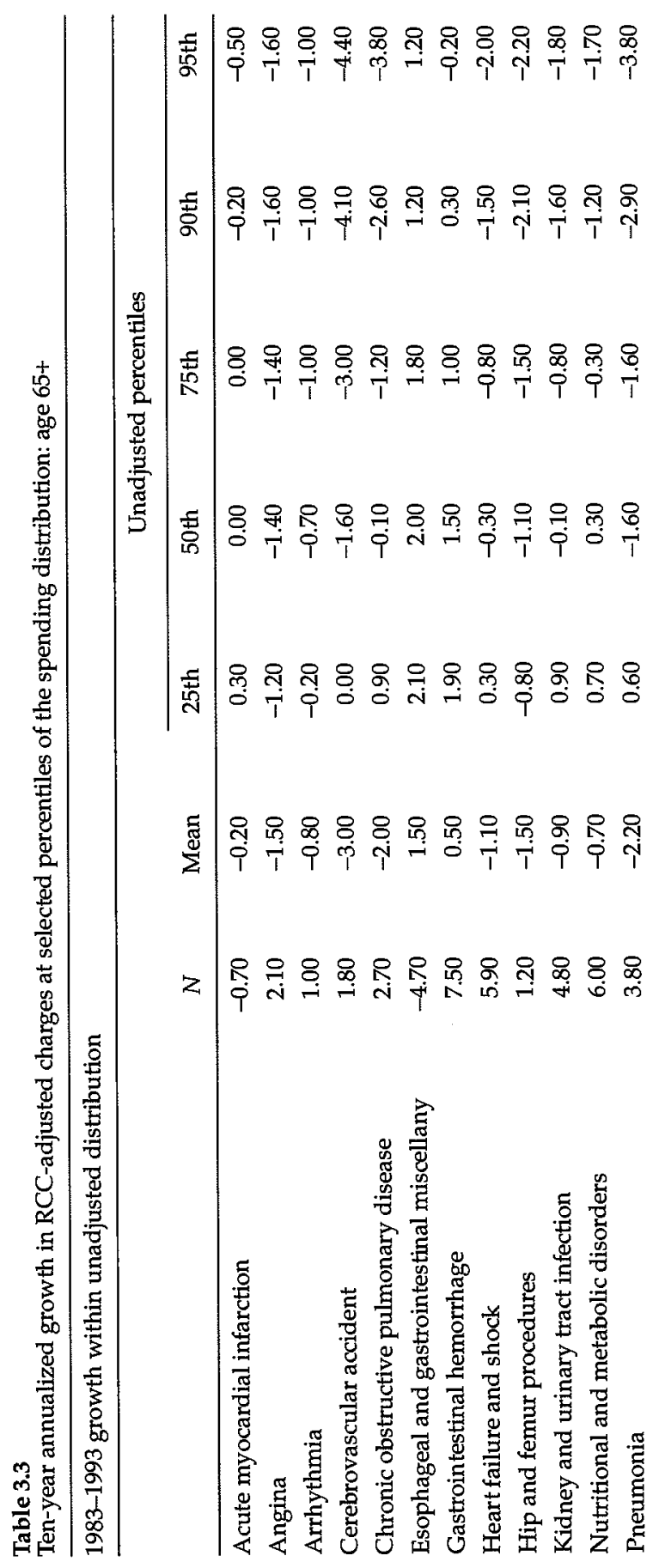




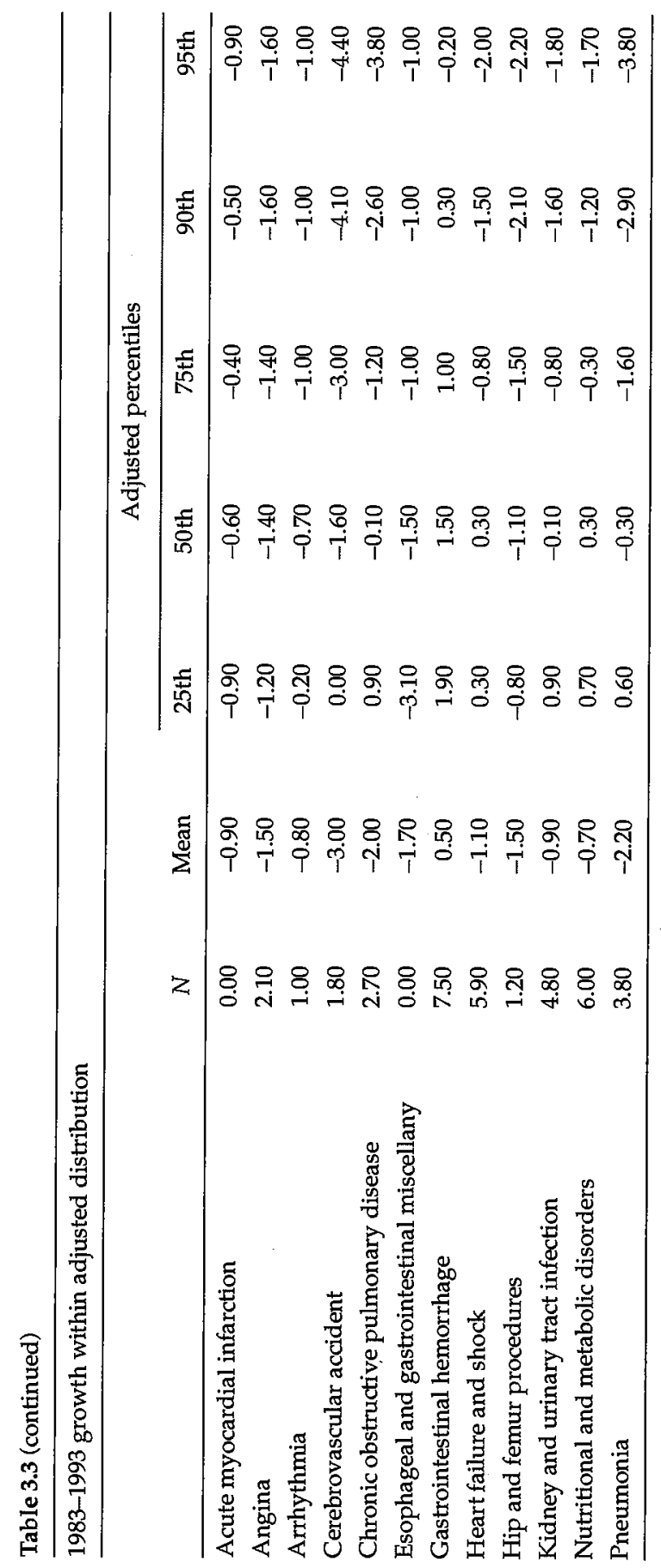




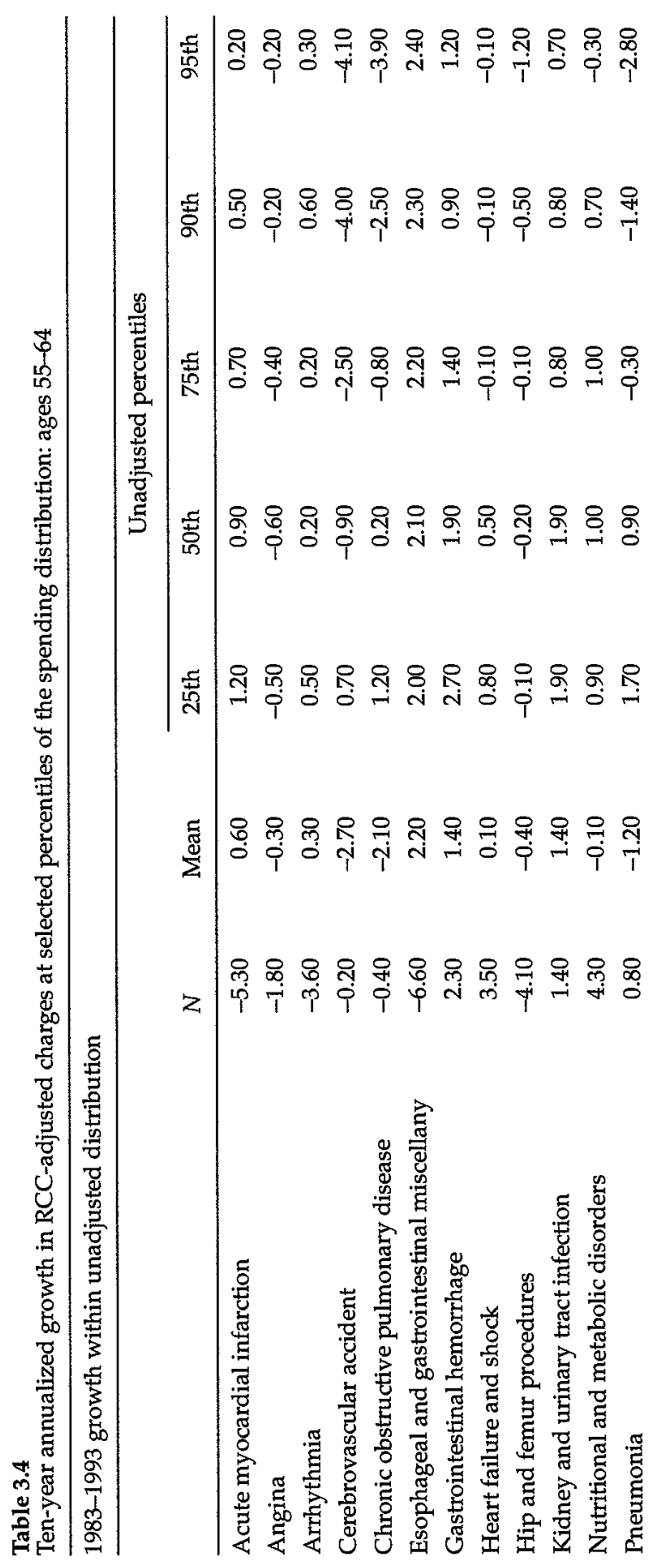




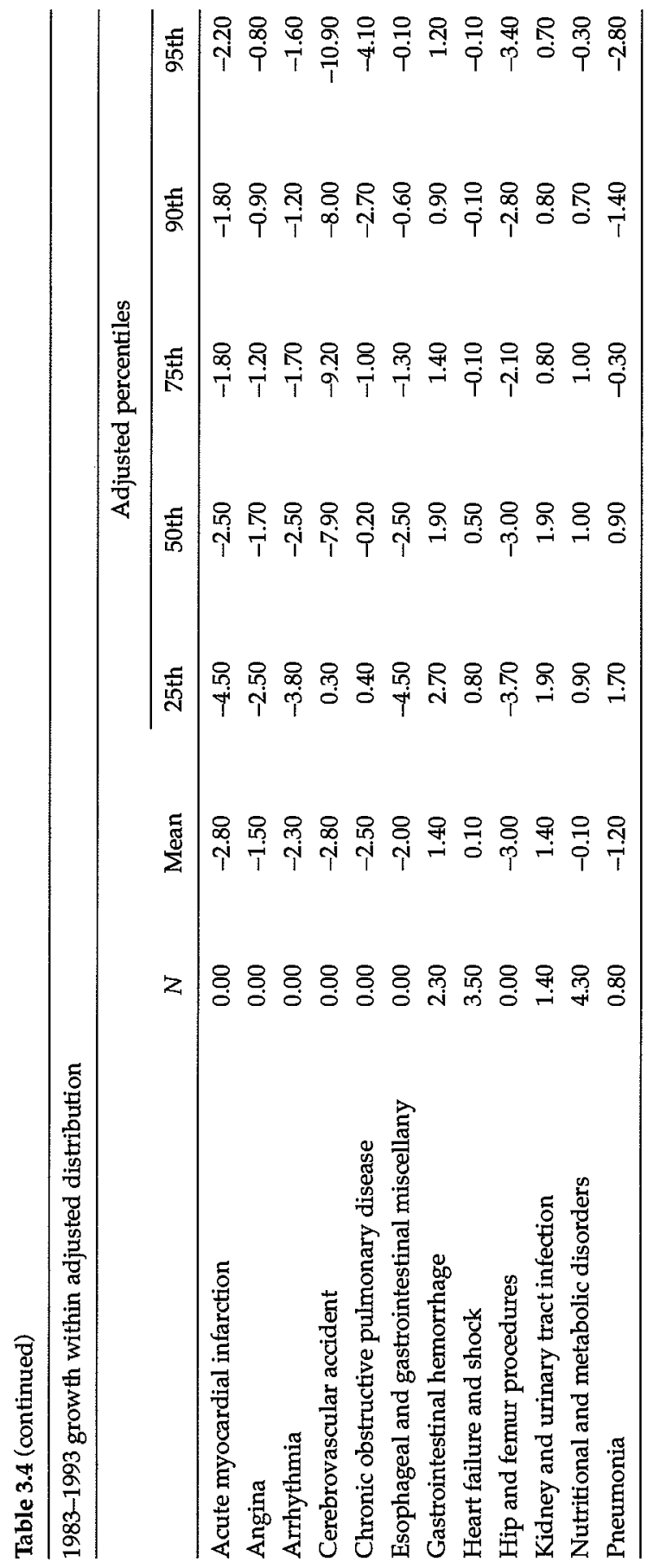


Table 3.5

Quantile regression parameter estimates: acute myocardial infarction, age 65+

\begin{tabular}{|c|c|c|c|c|c|}
\hline 1983 & $\begin{array}{l}25 \text { th } \\
\text { percentile }\end{array}$ & Median & $\begin{array}{l}75 \text { th } \\
\text { percentile }\end{array}$ & $\begin{array}{l}90 \text { th } \\
\text { e percentile }\end{array}$ & $\begin{array}{l}\text { 95th } \\
\text { percentile }\end{array}$ \\
\hline \multicolumn{6}{|l|}{ Patient level variables } \\
\hline \multicolumn{6}{|l|}{ Payer (omit: private and HMO) } \\
\hline Medicare & 310 & $449^{a}$ & $827^{\mathrm{b}}$ & $2,237^{\mathrm{a}}$ & 1,350 \\
\hline Medi-Cal & 207 & $547^{\mathrm{a}}$ & $1,239^{a}$ & $2,954^{\mathrm{a}}$ & 2,683 \\
\hline Other nonprivate & -165 & -197 & 509 & 804 & 1,634 \\
\hline \multicolumn{6}{|l|}{ Market level variables } \\
\hline Log physicians per capita & $494^{c}$ & $867^{\mathrm{c}}$ & $1,733^{\mathrm{C}}$ & $3,064^{\mathrm{c}}$ & $3,444^{\mathrm{a}}$ \\
\hline Log HMO enrollment ratio & -21 & 42 & 61 & 46 & -278 \\
\hline Log population & -78 & $-273^{c}$ & $-323^{c}$ & $-523^{b}$ & -672 \\
\hline Log income per capita & $1,232^{\mathrm{c}}$ & $1,568^{\mathrm{c}}$ & $1,372^{\mathrm{c}}$ & 893 & 621 \\
\hline \multicolumn{6}{|l|}{ Level of competition [omit low] $^{\mathrm{d}}$} \\
\hline Moderate & $327^{a}$ & $612^{c}$ & $1,123^{c}$ & $2,219^{\mathrm{a}}$ & $2,879^{\mathrm{a}}$ \\
\hline Competitive & $418^{a}$ & $899^{c}$ & $1,034^{\mathrm{c}}$ & $2,807^{\mathrm{C}}$ & $4,226^{a}$ \\
\hline Very competitive & $1,243^{c}$ & $2,327^{\mathrm{c}}$ & $3,775^{\mathrm{c}}$ & $7,232^{c}$ & $11,730^{c}$ \\
\hline \multicolumn{6}{|l|}{ Hospital level variables } \\
\hline Investor-owned (omit: NFP and other) & $374 \mathrm{c}$ & $-468^{c}$ & $-566^{c}$ & -690 & -797 \\
\hline Number of licensed beds & 0 & $2^{c}$ & $2^{c}$ & $4^{a}$ & $11^{\mathrm{c}}$ \\
\hline Total number of discharges (1983) & $0^{c}$ & $0^{c}$ & $0^{c}$ & $0^{\mathrm{b}}$ & $0^{\mathrm{b}}$ \\
\hline Teaching hospital (omit: nontech) & $607^{c}$ & $839^{c}$ & $1,042^{\mathrm{C}}$ & $1,809^{c}$ & $2,498^{\mathrm{c}}$ \\
\hline Constant & $-12,370$ & $-13,067$ & $-6,102$ & 6,976 & 17,089 \\
\hline 1993 & $\begin{array}{l}\text { perth } \\
\text { percenti }\end{array}$ & Median & percentile & $\begin{array}{l}90 \text { th } \\
\text { e percentile }\end{array}$ & $\begin{array}{l}\text { 95th } \\
\text { e percentile }\end{array}$ \\
\hline
\end{tabular}

Patient level variables

Payer (omit: private and HMO)

\begin{tabular}{lrrrrr} 
Medicare & $712^{c}$ & $1,017^{c}$ & $1,517^{c}$ & $2,384^{c}$ & $2,977^{c}$ \\
Medi-Cal & $1,125^{c}$ & $1,857^{c}$ & $2,726^{c}$ & $4,778^{c}$ & $9,405^{c}$ \\
Other nonprivate & -47 & 44 & 585 & 1,854 & 970 \\
arket level variables & & & & & \\
Log physicians per capita & -358 & $-575^{\mathrm{a}}$ & $-931^{\mathrm{a}}$ & -954 & $-1,947$ \\
Log HMO enrollment ratio & 15 & 32 & 67 & 0 & -14 \\
Log population & $356^{\mathrm{c}}$ & $628^{\mathrm{c}}$ & $1,037^{\mathrm{c}}$ & $1,737^{\mathrm{c}}$ & $2,892^{\mathrm{c}}$ \\
Log income per capita & $3,180^{\mathrm{c}}$ & $4,781^{\mathrm{c}}$ & $6,969^{\mathrm{c}}$ & $7,788^{\mathrm{c}}$ & $11,828^{\mathrm{c}}$ \\
\hline
\end{tabular}

Level of competition (omit low) ${ }^{\mathrm{d}}$

\begin{tabular}{lrrrrr} 
Moderate & $-642^{c}$ & $-1,048^{c}$ & $-1,623^{c}$ & $-1,903^{c}$ & $-4,222^{c}$ \\
Competitive & $-822^{c}$ & $-1,382^{c}$ & $-2,287^{c}$ & $-3,729^{c}$ & $-6,394^{c}$ \\
\hline & $-1,454^{c}$ & $-2,423^{c}$ & $-3,544^{c}$ & $-4,745^{c}$ & $-8,338^{c}$
\end{tabular}

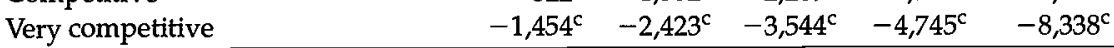

\begin{tabular}{lrrrrr}
\hline Hospital level variables & & & & & \\
Investor-owned (omit: NFP and other) & 135 & $260^{\mathrm{a}}$ & $693^{\mathrm{a}}$ & $1,718^{\mathrm{c}}$ & $2,998^{\mathrm{c}}$ \\
Number of licensed beds & $-1^{\mathrm{c}}$ & $-2^{\mathrm{c}}$ & $-3^{\mathrm{c}}$ & $-4^{\mathrm{c}}$ & $-8^{\mathrm{a}}$ \\
Total number of discharges (1983) & $0^{\mathrm{c}}$ & $0^{\mathrm{c}}$ & $0^{\mathrm{c}}$ & $0^{\mathrm{c}}$ & $0^{\mathrm{c}}$ \\
Teaching hospital (omit: nontech) & -28 & $255^{\mathrm{a}}$ & $666^{\mathrm{c}}$ & $1,222^{\mathrm{c}}$ & $1,244^{\mathrm{b}}$ \\
Constant & $-34,452^{\mathrm{c}}$ & $-52,872^{\mathrm{c}}$ & $-79,199^{\mathrm{c}}$ & $-92,734^{\mathrm{c}}$ & $-149,329^{\mathrm{c}}$ \\
\hline
\end{tabular}

a $p<0.10$

${ }^{\mathrm{b}} p<0.05$

c $p<0.01$

${ }^{d}$ Low $[1.00 \geq$ Herf $>0.20]$, moderate $[0.20 \geq$ Herf $>0.10]$, competitive $[0.10 \geq$ Herf $>0.05]$, very competitive $[0.05 \geq$ Herf] 


\begin{tabular}{|c|c|c|c|c|c|}
\hline 1983 & $\begin{array}{l}\text { 25th } \\
\text { percentile }\end{array}$ & Median & $\begin{array}{l}\text { 75th } \\
\text { percentile }\end{array}$ & $\begin{array}{l}90 \text { th } \\
\text { percentile }\end{array}$ & $\begin{array}{l}\text { 95th } \\
\text { percentile }\end{array}$ \\
\hline \multicolumn{6}{|l|}{ Patient level variables } \\
\hline \multicolumn{6}{|l|}{ Payer (omit: private and HMO) } \\
\hline Medicare & 126 & 106 & $438^{b}$ & $1,820^{\mathrm{c}}$ & $2,665^{a}$ \\
\hline Medi-Cal & 114 & $509^{c}$ & $864^{\mathrm{c}}$ & $2,956^{\mathrm{c}}$ & $6,865^{\mathrm{C}}$ \\
\hline Other nonprivate & -106 & -186 & -65 & 326 & 990 \\
\hline \multicolumn{6}{|l|}{ Market level variables } \\
\hline Log physicians per capita & 232 & 290 & $642^{\mathrm{b}}$ & 553 & 1,581 \\
\hline Log HMO enrollment ratio & 16 & -54 & $-48^{\mathrm{b}}$ & 42 & -172 \\
\hline Log population & -2 & -74 & -119 & -26 & -64 \\
\hline Log income per capita & $936^{c}$ & $1,804^{\mathrm{c}}$ & $1,922^{\mathrm{c}}$ & $2,158^{b}$ & 1,493 \\
\hline \multicolumn{6}{|l|}{ Level of competition [omit low] $^{\mathrm{d}}$} \\
\hline Moderate & 269 & $441^{\mathrm{a}}$ & $1,240^{\mathrm{c}}$ & $1,625^{\mathrm{b}}$ & $2,610^{b}$ \\
\hline Competitive & $623^{\mathrm{a}}$ & $987^{\mathrm{c}}$ & $1,461^{\mathrm{c}}$ & 1,264 & 2,469 \\
\hline Very competitive & $839^{a}$ & $1,955^{\mathrm{c}}$ & $3,268^{c}$ & $4,275^{\mathrm{c}}$ & $7,826^{c}$ \\
\hline \multicolumn{6}{|l|}{ Hospital level variables } \\
\hline Investor-owned (omit: NFP and other) & $-226^{b}$ & $-429^{c}$ & $-588^{c}$ & -658 & $-1,782^{b}$ \\
\hline Number of licensed beds & 0 & 1 & $3^{c}$ & 3 & 2 \\
\hline Total number of discharges (1983) & $0^{c}$ & $0^{\mathrm{c}}$ & $0^{\mathrm{a}}$ & 0 & $0^{b}$ \\
\hline Teaching hospital (omit: nontech) & $263^{a}$ & $646^{\mathrm{c}}$ & $1,519^{\mathrm{c}}$ & $2,708^{c}$ & $3,837^{\mathrm{c}}$ \\
\hline Constant & $-9,022^{a}$ & $-18,760^{c}$ & $-17,396$ & $-18,392$ & $-3,923$ \\
\hline
\end{tabular}

25th 75th 90th 95th

Patient level variables

Payer (omit: private and HMO)

\begin{tabular}{lrrrrr} 
Medicare & $331^{\mathrm{b}}$ & $583^{\mathrm{a}}$ & $946^{\mathrm{c}}$ & $3,222^{\mathrm{c}}$ & $4,274^{\mathrm{c}}$ \\
Medi-Cal & $443^{\mathrm{a}}$ & $886^{\mathrm{c}}$ & $1,728^{\mathrm{c}}$ & $3,321^{\mathrm{c}}$ & $6,131^{\mathrm{c}}$ \\
Other nonprivate & 242 & 527 & 749 & 924 & $1,457^{\mathrm{b}}$ \\
rket level variables & & & & & \\
og physicians per capita & $-1,038^{\mathrm{c}}$ & $-1,289^{\mathrm{c}}$ & -919 & $-1,424$ & $-3,497^{\mathrm{b}}$ \\
og HMO enrollment ratio & -87 & $-167^{\mathrm{b}}$ & $-271^{\mathrm{b}}$ & -177 & -651 \\
og population & $453^{\mathrm{c}}$ & $325^{\mathrm{b}}$ & $508^{\mathrm{a}}$ & $1,141^{\mathrm{a}}$ & $1,173^{\mathrm{a}}$ \\
og income per capita & $4,069^{\mathrm{c}}$ & $5,803^{\mathrm{c}}$ & $5,637^{\mathrm{c}}$ & $7,231^{\mathrm{a}}$ & $11,508^{\mathrm{c}}$ \\
\hline
\end{tabular}

\begin{tabular}{|lrrrrr|}
\hline Level of competition (omit low) $^{\mathrm{d}}$ & $4,069^{\mathrm{c}}$ & $5,803^{\mathrm{c}}$ & $5,637^{\mathrm{c}}$ & $7,231^{\mathrm{a}}$ & $11,508^{\mathrm{c}}$ \\
$\quad$ & & & & & \\
Moderate & $-914^{\mathrm{c}}$ & -903 & -326 & -271 & 1,001 \\
Competitive & $-1,049^{\mathrm{c}}$ & $-989^{\mathrm{a}}$ & $-1,606^{\mathrm{a}}$ & $-2,724^{\mathrm{a}}$ & 1,894 \\
Very competitive & $-1,811^{\mathrm{c}}$ & $-1,458^{\mathrm{a}}$ & $-1,827^{\mathrm{a}}$ & $-3,643^{\mathrm{a}}$ & $-1,814$ \\
\hline
\end{tabular}

Hospital level variables

Investor-owned (omit: NFP and other) $\quad 391^{\mathrm{c}} \quad 8^{\circ} 7^{\mathrm{c}} \quad 1,577^{\mathrm{c}} \quad 3,489^{\mathrm{c}} \quad 4,243^{\mathrm{c}}$

Number of licensed beds

Total number of discharges (1983)

Teaching hospital (omit: nontech)

$\begin{array}{rrrrr}391^{c} & 817^{c} & 1,577^{c} & 3,489^{c} & 4,243^{c} \\ -1 & 0 & 0 & 0 & -4 \\ 0^{c} & 0^{c} & 0^{c} & 0^{c} & 0^{a} \\ 148 & 385^{\mathrm{a}} & 547^{\mathrm{a}} & 1,295^{\mathrm{c}} & 2,548^{\mathrm{c}} \\ -48,210^{\mathrm{c}} & -63,669^{\mathrm{c}} & -59,541^{\mathrm{c}} & -83,656^{\mathrm{a}} & -137,415^{\mathrm{a}}\end{array}$

Constant $-48,210^{c}-63,669^{c}-59,541^{c}-83,656^{\mathrm{a}}-137,415^{\mathrm{a}}$

${ }^{\mathrm{a}} p<0.10$

${ }^{b} p<0.05$

$c^{c} p<0.01$

${ }^{d}$ Low $[1.00 \geq$ Herf $>0.20]$, moderate $[0.20 \geq$ Herf $>0.10]$, competitive $[0.10 \geq$ Herf $>0.05]$, very competitive $[0.05 \geq$ Herf] 


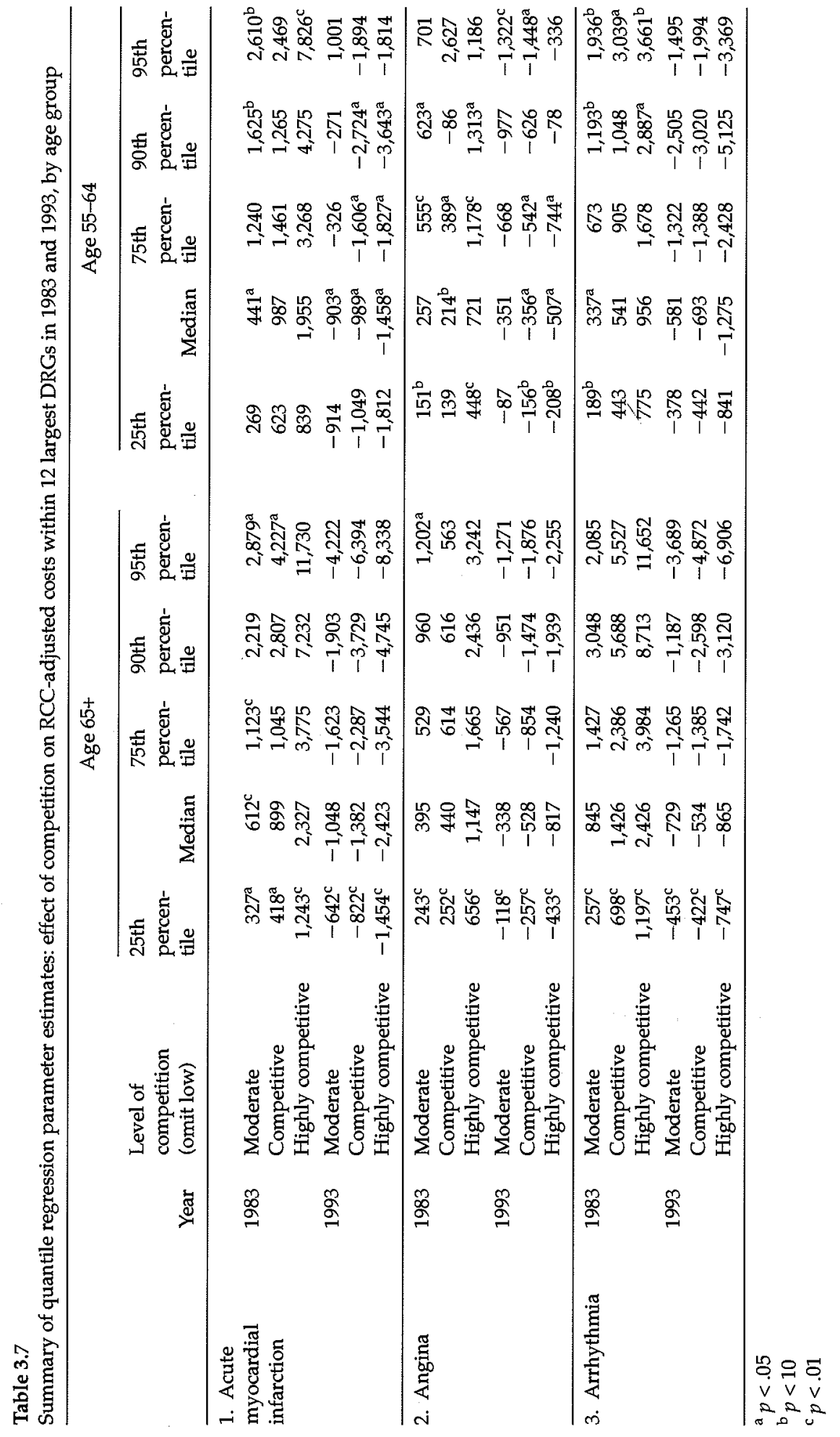




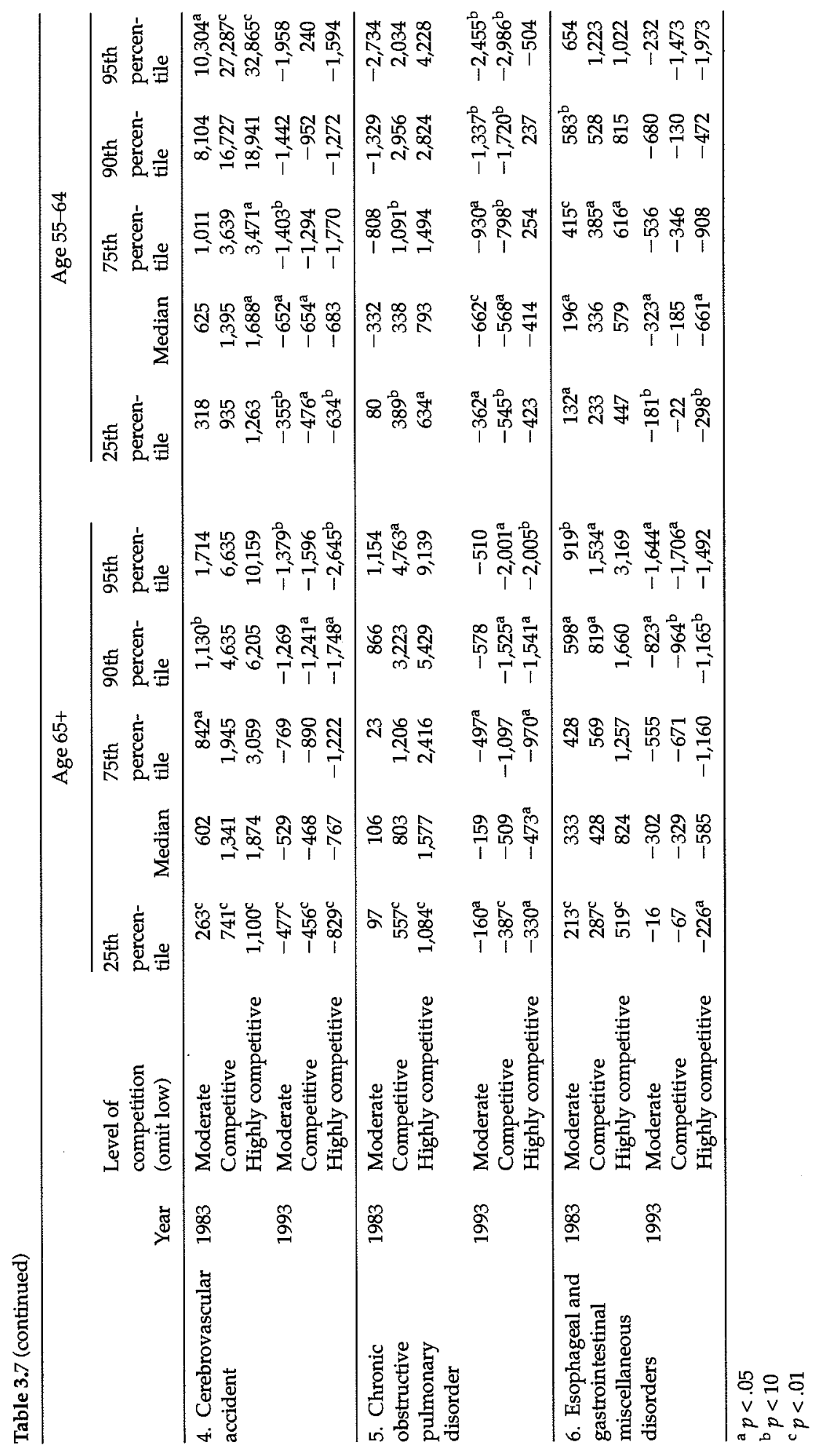




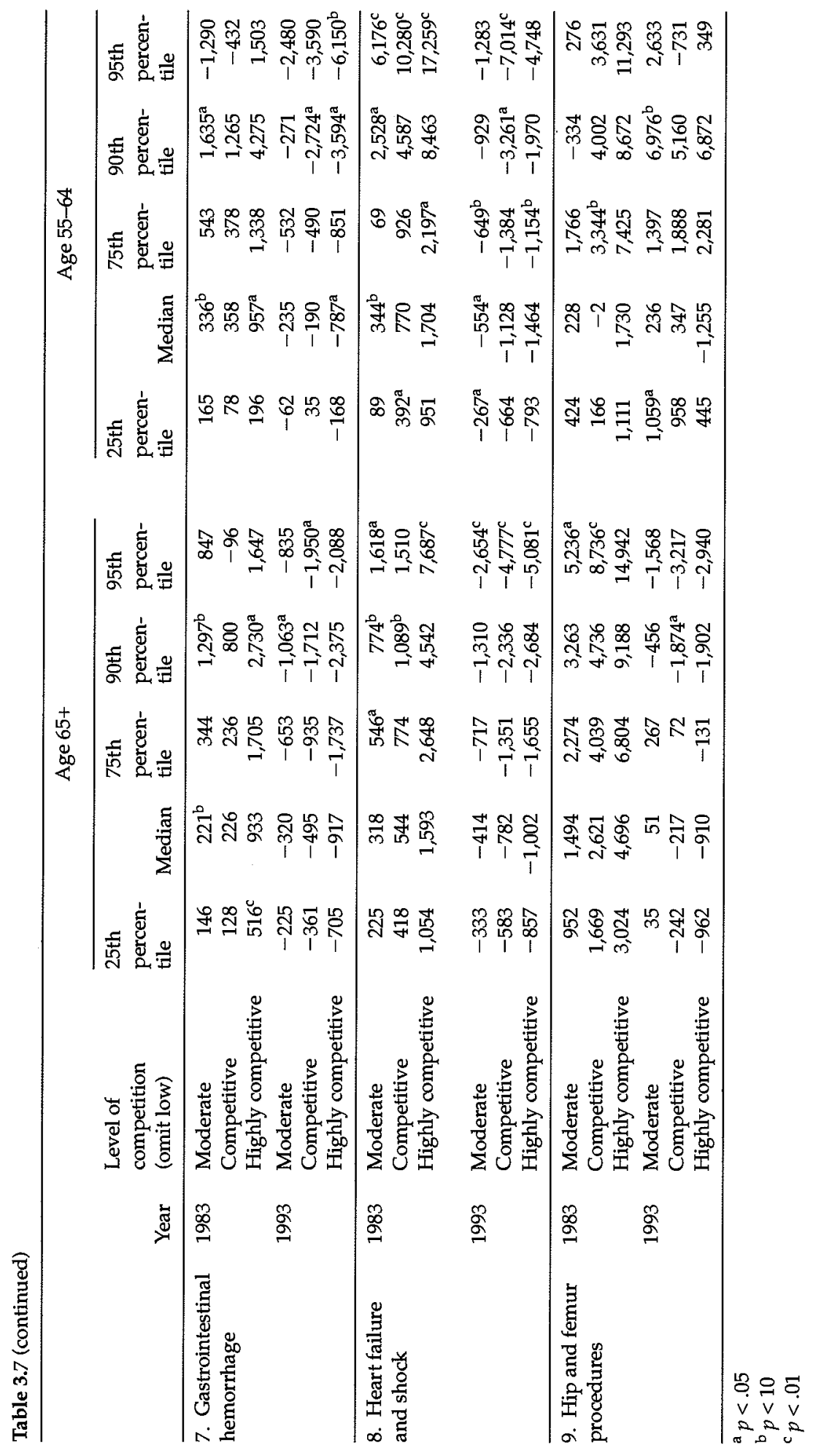




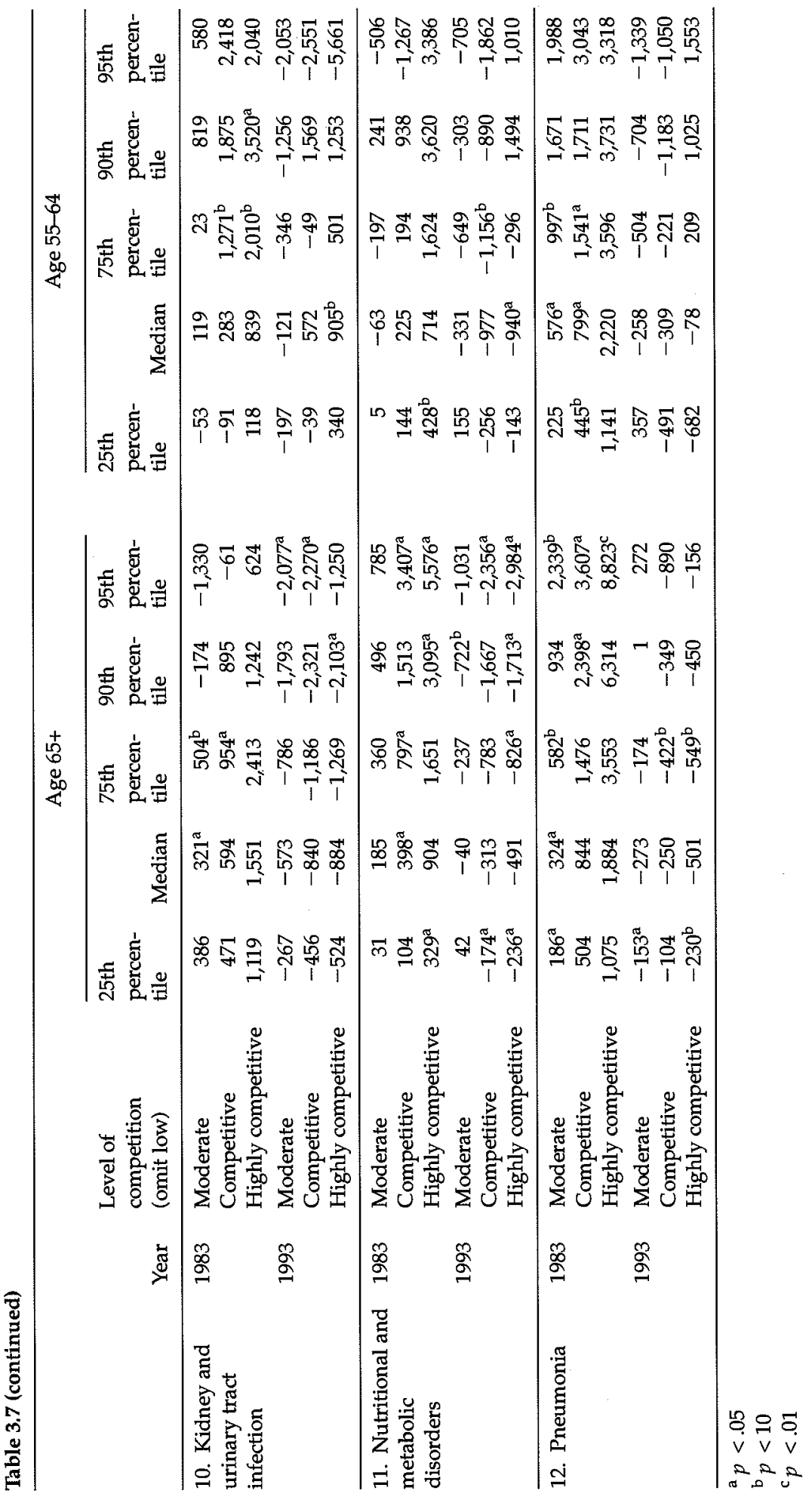


regressions for all twelve DRGs for 1983 and 1993, and for both age groups. Beginning with the left panel of table 3.7, we find that in 1983, in every case, costs rise with increasing competition, and particularly for the most expensive admissions. This is consistent with the "medical arms race" literature, which suggests that under the retrospective reimbursement system in place at the beginning of the period we study, a more competitive hospital market will raise costs as hospitals compete to attract doctors and their patients by offering added services (Robinson and Luft, 1985). In contrast, in 1993, increasing competitiveness is associated with decreased costs in all twelve DRGs. This is consistent with previous findings such as those of Melnick and Zwanziger (1988), who found that costs fell by more than 11 percent for hospitals in the most competitive markets in California during this period while actually rising in the least competitive markets. Not addressed in their findings, however, is the strong pattern we observe for the reductions in expenditures with increasing competition to increase progressively along the spending distribution, as predicted by the incentive structure of PPS to induce selective reduction of expenditures among the most expensive patients. Among the elderly, for example, AMI admissions at the 95th percentile are associated with an estimated $\$ 8,338$ reduction in hospital costs, compared to a reduction of $\$ 1,454$ in costs at the 25 th percentile.

The columns of table 3.7 labeled age 55-64 repeats the above analyses for the younger age group. In general, we still find strong positive effects of competition on costs in 1983, but in 1993, we find much smaller negative effects of competition on costs that are statistically significant for only four of the twelve DRGs. Several DRGs also show a statistically insignificant trend toward lower costs with competition. This raises the question of whether some of the difference is due to reduced sample size. However, increasing the sample analyzed to include all persons below age 65, or adding additional years of data (for example, 1992), did not meaningfully alter these results. This suggests that whatever forces led to changes in the distribution of hospital expenditures in these diagnoses among the elderly between 1983 and 1993 may have also affected patients younger than age 65, although the effects do not appear to have been as powerful.

\section{Adjustments for Changes in Discharge Rates}

To address the concern that percentiles in one year may not be comparable to percentiles in another year due to changes in severity of ill- 
ness, especially due to declines in admission rates as described previously, we also examined quantile regressions for DRGs in which admission rates fell from 1983 to 1993, and thus limited the number of observations in 1983 to the number in 1993, to compare "comparable patients" assuming no change in the underlying distribution of disease. These results were not substantively different from the regressions reported in tables 3.5 through 3.7 .

\section{Summary and Conclusion}

Using annual patient discharge data from all nonfederal, acute-care hospitals in the state of California from 1983 and 1993, we examined growth in hospital costs and the effects of competition on costs at various points in the spending distribution for persons above and below age 65 in the twelve largest DRGs. Our analyses of cost growth show cost growth falling with increasing position in the spending distribution in every DRG we studied, as predicted by the effects of Medicare PPS. However, a very similar pattern is also evident among admissions of patients age 55-64. Our analyses of the effects of competition show a strong trend for increasing competition to increase expenditures in all age groups in 1983, with increasing effects at higher locations in the spending distribution. Our analyses for those older than age 65 in 1993 show the opposite pattern, however, with increasing competition associated with decreased costs, and the effects far larger among the most expensive patients. This pattern is not as pronounced among those younger than age 65 , suggesting that spending on persons older than age 65 during this period may have been subject to some forces different than those affecting spending on persons younger than age 65 .

These findings are broadly consistent with the model of provider behavior under alternative reimbursement schemes that we present. This predicts a tendency for hospitals to skimp on unprofitable patients and to milk profitable patients under fixed-rate prospective reimbursement. Although several studies have documented lower resource utilization associated with fixed-rate reimbursement systems, fewer have considered the possibility that such reductions might differentially affect profitable and unprofitable classes of patients, and none have demonstrated these patterns of increasing cost reductions among high-cost patients for Medicare PPS or shown that these reductions rise with increasing competition.

Certainly, the establishment of PPS and its associated incentives to decrease costs among the most costly patients is a plausible explana- 
tion for the patterns we observe among the elderly, but several other possible explanations are worth considering. One explanation is that there were changes in particular medical technologies or in the underlying severity of illness among the elderly over this period, and that these changes somehow selectively reduced expenditures for the high-cost elderly relative to the low-cost elderly. The fact that we see a fairly similar pattern of growth among the young is somewhat suggestive of this alternative account. It is not clear why this is the case, but it is highly plausible that practice patterns are likely to be similar for older and younger patients, so that incentives implicit in PPS end up affecting practice patterns for patients below age 65 as well. If the changes in spending we observe are explained by some specific change in underlying severity of illness or medical technology, it is not clear why such changes should occur over such a broad range of diagnoses or why they should be associated with increased competition. Also, in additional analyses, we stratified the elderly according to age and controlled for measurable aspects of underlying comorbidity and found no changes in our results.

Another possibility is that our results reflect changes in coding practices under Medicare, often referred to as "DRG creep." We have tried to address this concern in our analysis by combining related DRGs with and without complications, but it is possible that this does not capture all the changes that could have occurred. Indeed, one particular concern is that the development of the tracheostomy DRG in 1991 for patients requiring mechanical ventilation may have drawn some expensive patients out of the upper part of the distribution of costs from some of our DRGs. While this is important to consider, the fraction of all admissions coded into the tracheostomy DRG is only 0.1 percent to 0.2 percent. This seems to explain the broad changes we see across the spending distribution for such a broad range of diagnoses. In addition, some of the pattern we identify is clearly present by 1991, when the tracheostomy DRG was just being introduced. It is somewhat surprising that such recoding would be present only in the most competitive markets, though that would also certainly be of interest if it were the case. It should also be noted that, to the extent that some of our diagnoses may be more highly reimbursed than other closely related diagnoses, they may also be the recipients of upcoding, in which case one would expect expenditures at the lower end of the distribution to decline as healthier patients are added to the distribution.

Finally, it should be noted that our finding that cost reductions are greatest for the most expensive patients can also be interpreted as sim- 
ply reflecting the idea that it is easier to save large amounts of money where more money is spent. We are sympathetic to this concern, but note that we find a similar pattern of reductions in DRGs that are more expensive as well as in DRGs that are less expensive. It is not always the case that it is easier to decrease spending where more money is spent. To illustrate, analysis of data from a natural experiment comparing the cost of hospital care provided by doctors who specialize in inpatient care to hospital care by doctors who spend only a small fraction of their time taking care of inpatients reveals no evidence that cost savings differed across the distribution of costs (Meltzer et al. 2000).

With an understanding of the limitations of our analysis, it appears that increasing competition in the context of prospective payment is associated with selective reductions of expenditures for the most expensive patients. Whether this is desirable is impossible to determine without an analysis of the effects on outcomes. Nevertheless, our results suggest several clear lines for such analysis.

First, the possibility that costs are selectively reduced for the most costly patients suggests that outcomes may be selectively affected. While more than a few studies have examined the effects of prospective payment on outcomes (for example, Rodgers et al. 1990 and accompanying articles, Cutler 1995), none has stratified outcomes according to patient cost. Our results suggest that such analyses might be very useful because it is possible that adverse effects among the most costly patients might be masked by their inclusion with less costly patients, whose outcomes may even improve if increased resources allocated to attracting them to a particular hospital have some positive (albeit small) effect on outcomes. The same conclusion applies for attempts to measure the effects of competition on outcomes (see, for example, Kessler and McClellan 1999).

Our results also have important implications for measuring the quality of care under prospective payment systems, and especially in competitive environments, because they suggest that high-cost patients may be at particular risk in such contexts. Thus, it is important that quality measures reflect the concerns of that potentially vulnerable group. Even when a single measure of quality is used, our findings may have implications for how to measure quality of care. For example, our findings may provide a justification to prefer outcomes measures to process measures because process measures can suggest that quality is high over the whole population when the quality of care for certain parts of the population are actually poor. On the other hand, 
outcomes are often favorable for less severely ill (less costly) patients in any case, so expending greater resources on them is unlikely to improve outcomes. It is worth noting that this basic conclusion remains, regardless of whether one believes that cost reductions were largest among the most costly patients due to selective incentives within a prospective payment, or whether one simply believes that cost reductions are largest for the most costly patients simply because, as the old adage goes, "that's where the money is." A related issue is whether the effects of competition on costs should be interpreted as reducing quality or, rather, improving efficiency. Resolution of this question will be possible only with data that permits a comprehensive assessment of outcomes.

It should be noted that the combination of prospective payment and competition studied here is not unique to Medicare PPS, but in fact, is the basic idea behind the increasing use of capitated managed-care arrangements and competition to control costs, including Medicare managed care. Indeed, such managed competition arrangements present similar incentives to expend resources to attract less costly participants while avoiding more costly ones. It is not difficult to imagine that these incentives result in substantial investments in wellness programs and preventive services, amenities that improve access for working persons, reductions in copayments, etc., that would attract relatively healthy participants. Even casual observation of the offerings of health maintenance organizations leaves little question that many of these benefits are indeed occurring, but whether such expenditures are an efficient use of health care resources and how they may affect the care received by the most severely ill are important questions for future work. This is especially true given evidence that quality of care in HMOs may be the worst for patients who are chronically ill (Miller and Luft 1997), and that HMOs may limit expenditures for severely ill persons in intensive care (Rapoport et al. 1992, Cher and Lenert 1997).

Finally, it should be noted that various approaches can be tried to improve upon existing prospective payment systems, for example, risk adjustment and the use of blended payment schemes that include both prospective and retrospective components designed to mitigate incentives for patient selection or discrimination in care provision. Indeed, the Medicare PPS has always tied reimbursement to the amount of care provided to some extent, and thus never truly became fully prospective (McClellan 1997). Proposals have been seriously considered to expand this retrospective aspect of Medicare PPS as well as to improve 
risk adjusters by developing a DRG system that allows a finer classification of admissions (Newhouse, Buntin, and Chapman 1997). Our work provides support for the value of further examination of both approaches.

\section{Notes}

1. For standard textbook discussion, see Peter Zweifel and Friedrich Breyer (1997), Health Economics, NY: Oxford Press, and Charles Phelps (1997), Health Economics Second Ed., Reading, MA: Addison Wesley.

2. By annual volume of discharges within DRGs.

3. For a good summary of the cost-containment effort in California during the 1980s, see Langa 1992.

4. A detailed overview on forms of managed care can be found in Gold et al. 1995.

5. In practice, this may be implemented by increasing spending on infrastructural elements that may be most important to health patients (such as a pleasant cafeteria or waiting area), and decreasing spending on infrastructure that is most important to the sickest patients (such as expensive imaging machines or intensity of ICU care). It might also be implemented by reducing pressure on physicians to discharge relatively healthy patients quickly.

6. The classic example of this is the free car seat sometimes offered to expectant parents to induce them to deliver their child at a particular hospital.

7. Note, however, that the relationship between competition and quality in general may be much more complex than this in settings where both price and quantity may be varied because it will also depend on the complementarity between quantity and quality (Spence 1975, Saving 1982). Another alternative view is reflected in Satterthwaite (1979), in which an increasing number of sellers in a market effectively raises search costs by decreasing the value of information held by any individual about a particular seller.

8. Discharges from managed care facilities exempted from standard accounting requirements were identified in the data by a zero in the field for total charges, although actual charges were nonzero. In total, this involves omitting 8.8 percent of discharges.

9. A large amount of literature defines hospital markets for the purpose of measuring competition. Traditional measures have included market definitions based on geopolitical boundaries such as counties or metropolitan statistical areas (for example, Joskow 1980), distance (Robinson and Luft 1985), or patient flows (for example, Melnick and Zwanziger 1988). These measures have all been criticized for varying reasons, including the (ir)relevance of geopolitical boundaries or distance with respect to competition, and the endogeneity of patient flows. While some newer approaches (for example, Kessler and McClellan 1999) have tried to address these concerns, such approaches are substantially more difficult to implement, and their merits have not yet been demonstrated. While a comparison of multiple measures of competition would be of value, we defer it for future work.

10. See also Stigler (1968) and Cowling and Waterson (1976) for a theoretical rationale for the use of the HHI. 
11. Another possibility would be to analyze the effects of competition on cost growth within ICD-9 codes (International Classification of Disease, 9th ed.). However, we elected not to do this because the incentives created by Medicare PPS that may differentially affect high- and low-cost patients refer to high- and low-cost patients within DRG groups rather than within ICD-9 codes.

12. Specifically, we calculated the Charlson comorbidity index based on secondary diagnoses for the index admission, and found that the distribution of scores shifted upward in all our DRGs (Charlson et al. 1987, Deyo and Romano 1993, Romano et al. 1993).

\section{References}

Allen, R., and P. Gertler (1991). "Regulation and the Provision of Quality to Heterogeneous Consumers: The Case of Prospective Pricing of Medical Services," Journal of Regulatory Economics, 3:361-375.

Bain, J. (1951). "Relationship of Profit Rate to Industry Concentration: American Manufacturing, 1936-1940," Quarterly Journal of Economics, 65:293-324.

Carter, G., J. Newhouse, and D. Relles (1990). "How Much Change in the Case Mix Index Is DRG Creep?" Journal of Health Economics, 9:411-428.

Charlson, M., P. Pompei, K. Ales, and C. McKenzie (1987). "A New Method of Classifying Prognostic Comorbidity in Longitudinal Studies: Development and Validation," Journal of Chronic Disease, 40:373-383.

Cher, D., and L. Lenert (1997). "Method of Medicare Reimbursement and the Rate of Potentially Ineffective Care of Critically Ill Patients," JAMA, 278(12):1001-1007.

Cowling, K., and M. Waterson (1976). "Price-Cost Margins and Market Structure," Econometrica, 43(171):267-274.

Cutler, D. (1995). "The Incidence of Adverse Medical Outcomes Under Prospective Payment," Economica, 63(1):29-50.

Cutler and Meara (1998). "The Medical Costs of the Young and Old: A Forty-Year Perspective," in Frontiers in the Economics of Aging, David A. Wise, ed. (Chicago, IL: University of Chicago Press, pp. 215-242).

Davis, K., et al. (1990). Health Care Cost Containment, Baltimore, MD: Johns Hopkins University Press.

Davis, M., and S. Burner. (1995). "Three Decades of Medicare: What the Numbers Tell Us," Health Affairs, 14(4):231-243.

Deyo, R., D. Cherkin, and M. Ciol. (1992). "Adapting a Clinical Comorbidity Index for Use with ICD-9-CM Administrative Databases." Journal of Clinical Epidemiology. 45(6):613-619.

Dranove, D. (1987). "Rate-Setting by Diagnosis-Related Groups and Hospital Specialization," RAND Journal of Economics, 18(3):417-427.

Dranove, D., M. Shanley, and C. Simon (1992). "Is Hospital Competition Wasteful?" RAND Journal of Economics, 23(2):247-262.

Dranove, D., M. Shanley, and W. White. (1991). "How Fast are Hospital Prices Really Rising?" Medical Care. 29(8):690-696. 
Dranove, D., and W. White (1994). "Recent Theory and Evidence on Competition in Hospital Markets," Journal of Economics and Management Strategy, 3(1):169-209.

Dranove, D., and W. White (1998). "Medicaid-Dependent Hospitals and Their Patients: How Have They Fared?" Health Services Research, 32(2):163-185.

Ellis, R. (1998). "Creaming, Skimping, and Dumping: Provider Competition on the Intensive and Extensive Margins," Journal of Health Economics, 17:537-555.

Ellis, R., and T. McGuire (1986). "Provider Behavior Under Prospective Reimbursement," Journal of Health Economics, 5:129-151.

Ellis, R., and T. McGuire (1996). "Hospital Response to Prospective Payment: Moral Hazard, Selection, and Practice-Style Effects," Journal of Health Economics, 15(3):257-277.

Finkler, S. (1982). "The Distinction Between Costs and Charges," Annals of Internal Medicine, 96(1):102-109.

Gold, M., et al. (1995). "Behind the Curve: A Critical Assessment of How Little Is Known About Arrangements Between Managed Care Plans and Physicians," Medical Care Research and Review, 52(3):304-341.

Hodgkin, D., and T. McGuire (1994). "Payment Levels and Hospital Response to Prospective Payment," Journal of Health Economics, 13:1-29.

Hornbrook, M., and J. Rafferty (1982). "The Economics of Hospital Reimbursement." Advances in Health Economics and Health Services Research, 3:79-115.

Institute of Medicine (1997). Managing Managed Care: Quality Improvement in Behavioral Health, Washington, D.C.: National Academy Press.

Johns, L. (1985). "Selective Contracting in California," Health Affairs, 4(3):32-48.

Johns, L. (1989). "Selective Contracting in California: An Update," Inquiry, 26:345-353.

Joskow, P. (1980). "The Effects of Competition and Regulation on Hospital Bed Supply and the Reservation Quality of the Hospital," Bell Journal of Economics, 11(2):421-447.

Kessler, D., and M. McClellan (1999). "Ts Hospital Competition Socially Wasteful?" NBER Working Paper 7266, NBER, Cambridge, MA.

Langa, K. (1992). Medicaid Cost-Containment in the 1980s: Did It Encourage Interpayer Differences in Hospital Care? Unpublished dissertation. University of Chicago, Chicago, IL.

Langa, K., and E. Sussman (1993). "The Effect of Cost-Containment Policies on Rates of Coronary Revascularization in California," The New England Journal of Medicine, 329(24):1784-1789.

Luft, H., and R. Miller (1988). "Patient Selection in a Competitive Health Care Environment," Health Affairs, 7(3):97-119.

Manning, W. et al. (1984). "A Controlled Trial of the Effect of a Prepaid Group Practice on Use of Services," The New England Journal of Medicine, 310(23):1305-1310.

McClellan, M. (1997). "Hospital Reimbursement Incentives: An Empirical Analysis," Journal of Economics and Management Strategy, 6(1):91-128.

Melnick, G., et al. (1992). "The Effects of Market Structure and Bargaining Position on Hospital Prices," Journal of Health Economics, 11:217-233. 
Melnick, G., and J. Zwanziger (1988). "The Effects of Hospital Competition and the Medicare PPS Program on Hospital Cost Behavior in California," Journal of Health Economics, 7(4):301-320.

Melnick, G., and J. Zwanziger. (1995). "State Health Care Expenditures Under Competition and Regulation, 1980 Through 1991," American Journal of Public Health, 85(10):1391-1396.

Meltzer, D., et al. (2000). "Effects of Medical Specialization on Costs and Outcomes in a General Medicine Service: Results of a Randomized Trial of Hospitalists." Unpublished manuscript.

Meltzer, D., and J. Chung (2000). "Cost Growth Among High- and Low-Cost Hospital Admissions Under Cost-Containment: Evidence from California, 1983-1994." Unpublished manuscript.

Miller, R., and H. Luft (1997). "Does Managed Care Lead to Better or Worse Quality of Care?" Health Affairs, 16(5):7-25.

Newhouse, J. (1989). "Do Unprofitable Patients Face Access Problems?" Health Care Financing Review, 11(2):33-42.

Newhouse, J., M. Buntin, and J. Chapman (1997). "Risk Adjustment and Medicare: Taking a Closer Look," Health Affairs, 16(5):26-43.

Newhouse, J. P., S. Cretin, and C. J. Witsberger (1989). "Predicting Hospital Accounting Costs," Health Care Financing Review, 11(1):25-33.

Office of Statewide Health Planning and Development (1993). Accounting and Reporting Manual for California Hospitals, Second Edition. Sacramento, CA: OSHPD.

Rapoport, J., et al. (1992). "Resource Utilization Among Intensive Care Patients: Managed Care Versus Traditional Insurance," Archives of Internal Medicine, 152:2207-2212.

Robinson, J., and H. Luft (1985). "The Impact of Hospital Market Structure on Patient Volume, Average Length of Stay, and the Cost of Care," Journal of Health Economics, 4:333-356.

Robinson, J., and C. Phibbs (1989). "An Evaluation of Medicaid Selective Contracting in California," Journal of Health Economics, 8:437-455.

Rodgers, W., et al. (1990). "Quality of Care Before and After Implementation of the DRG-Based Prospective Payment System: A Summary of Effects," JAMA, 264(15):1989-1994.

Romano, P., L. Roos, and J. Jollis. (1993). "Adapting a Clinical Comorbidity Index for Use with ICD-CM Administrative Data: Differing Perspectives." Journal of Clinical Epidemiology. 46:1075-1079.

Russell, L., and C. Manning (1989). "The Effect of Prospective Payment on Medicare Expenditures," The New England Journal of Medicine, 320(7):439-444.

Satterthwaite, M. (1979). "Consumer Information, Equilibrium Industry Price, and the Number of Sellers," Bell Journal of Economics, 10(2):483-502.

Saving, T. (1982). "Market Organization and Product Quality," Southern Economic Journal, 48(4):855-867.

Schwartz, M., D. Young, and R. Siegrist (1995). "The Ratio of Costs to Charges: How Good a Basis for Estimating Costs?" Inquiry, 32:476-481. 
Smith, H., and M. Fottler (1985). Prospective Payment: Managing for Operational Effectiveness. Rockville, MD: Aspen Systems Corporation.

Sohn, M. (1996). From Regional to Local Markets: Network Study of Competition in California Hospital Markets. Unpublished dissertation. University of Chicago, Chicago, IL.

Spence, A. (1975). "Monopoly, Quality, and Regulation," Bell Journal of Economics, $6: 417-429$.

Stafford, R. (1990). "Cesarean Section Use and Source of Payment: An Analysis of California Hospital Discharge Abstracts," American Journal of Public Health, 80(3):313-315.

Stigler (1968). The Organization of Industry. Homewood, IL: R. D. Irwin.

Tirole, J. (1988). The Theory of Industrial Organization. Cambridge, MA: MIT Press.

U.S. Department of Commerce, Bureau of the Census (1993). Revised Estimates of the Population of Counties by Age, Sex, and Race [United States]: 1890-1989 [Computer File]. Washington, D.C.: U.S. Department of Commerce, Bureau of the Census [Producer], 1992. Ann Arbor, MI: Inter-University Consortium for Political and Social Research [Distributor], 1993.

U.S. Department of Commerce, Bureau of the Census (1998). Estimates of the Population of Counties by Age, Sex, Race, and Hispanic Origin [United States]: 1990-1996 [Computer File]. Washington, D.C.: U.S. Department of Commerce, Bureau of the Census [Producer], 1998. Ann Arbor, MI: Inter-University Consortium for Political and Social Research [Distributor], 1998.

White, L. (1972). "Quality Variation When Prices Are Regulated," Bell Journal of Economics, 3:425-436. 